\title{
Strength Prediction of Epoxy Adhesively Bonded Scarf Joints of
}

\section{Dissimilar Adherends}

\section{Mohd Afendi $^{\mathrm{a}, \mathrm{b}, *}$, Tokuo Teramoto ${ }^{\mathrm{a}}$, Hairul Bin Bakri ${ }^{\mathrm{c}}$}

${ }^{\mathrm{a}}$ Graduate School of Systems and Information Engineering, University of Tsukuba,

Tennoudai 1-1-1, Tsukuba, Ibaraki, 305-8573 JAPAN

${ }^{\mathrm{b}}$ School of Mechatronic Engineering, Universiti Malaysia Perlis, Arau, Perlis, 02600 MALAYSIA

${ }^{\mathrm{c}}$ Faculty of Mechanical Engineering, Universiti Teknikal Malaysia Melaka,

Locked Bag No. 1752 Pejabat Pos Durian Tunggal, Durian Tunggal, Melaka, 76109 MALAYSIA

*Corresponding author. Tel.: +81-298-53-5242; fax: +81-298-53-5207

Email address: s0830194@u.tsukuba.ac.jp (Mohd Afendi) 


\section{Abstract}

In this study, strength of epoxy adhesively bonded scarf joints of dissimilar adherends, namely SUS304 stainless steel and YH75 aluminium alloy is examined on several scarf angles and various bond thicknesses under uniaxial tensile loading. Scarf angle, $\theta=45^{\circ}, 60^{\circ}$ and $75^{\circ}$ are employed. The bond thickness, $t$ between the dissimilar adherends is controlled to be ranged between $0.1 \mathrm{~mm}$ and $1.2 \mathrm{~mm}$. Finite element (FE) analysis is also executed to investigate the stress distributions in the adhesive layer of scarf joints by ANSYS 11 code. As the results, the apparent Young's modulus of adhesive layer in scarf joints is found to be $1.5 \sim 5$ times higher than those of bulk epoxy adhesive, which has been obtained from tensile tests. For scarf joint strength prediction, the existing failure criteria (i.e. maximum principal stress and Mises equivalent stress) can not satisfactorily estimate the present experimental results. Though the measured stress multiaxiality of scarf joints proportionally increases as the scarf angle increases, the experimental results do not agree with the theoretical values. From analytical solutions, stress singularity exists most pronouncedly at the steel/adhesive interface corner of joint having $45^{\circ}$ to $75^{\circ}$ scarf angle. The failure surface observations confirm that the failure has always initiated at this apex. This is also in agreement with stress-y distribution obtained within FE analysis. Finally, the strength of scarf joints bonded with brittle adhesive can be best predicted by interface corner toughness, Hc parameter.

Key words: bond thickness; scarf angle; singularity; dissimilar adherends; interface mechanics; FEM 


\section{Introduction}

Adhesive joint is definitely the ideal substitute for any conventional bonding methods (e.g. rivet, welding, diffusion bonding, etc.) in structural engineering and industrial applications. To extend the exploitation of adhesive joints the evaluation of strength and failure mechanisms becomes very crucial. However, strength and failure behavior of adhesive joints are not only complex and but also depend extremely on the mechanical properties of the adhesive layer and the state of stresses inside it as imposed by the constraint effect of stiff adherends [1-3]. Therefore, in the literature, many works have been devoted on elucidating the critical factors affecting the reliability and integrity of sandwiched adhesive joints. These include investigations upon the effect of joint geometry (i.e. bond thickness, rigid or flexible substrate, scarf angle, spew fillet and etc.), loading rate and temperature.

The effect of bond thickness upon the strength of adhesive joint has been investigated extensively by numerous researchers for many years. Zhu and Kedward [4] analyzed the effect of bond thickness and fillet upon the titanium single and double lap joints using finite element method and closed-form solutions. Their parametric studies revealed that the maximal strength of lap joints of ductile adhesive increased with decreasing bond thickness. Taib et al. [5] studied the effect of bond thickness on L-section joints of composite adherends using two components structural paste adhesive Hysol EA 9359.3. They attributed the decreased failure load to increasing bond thickness in terms of the stress state (i.e. plane stress or plane strain) prevailing inside the adhesive layer: the thin bond thickness favors plane stress while thick bond thickness favors plane strain state. More 
recently, Davies et al. [6] examined the physico-chemical and mechanical behavior of aluminium substrates bonded with commercial epoxy adhesive joints of several thicknesses. They noted a small reduction in the mechanical properties of adhesive layer as the bond thickness was increased. They also explained this feature by a change in the stress state as the modified Arcan fixtures of thick adhesive layer were tested within their numerical analysis results.

In general, the strength of adhesive joints increases as the bond thickness decreases [7]. However, this is not necessarily true. Park et al. [8] tested thick aluminium lap joint specimens with four different adhesive film thicknesses and predicted the strength based on modified damage zone ratio method. According to their experimental results, failure load of lap joints without defects increases as bond thickness increases from 0.15 to $0.45 \mathrm{~mm}$ and then gradually decreases when the bond thickness reaches $0.9 \mathrm{~mm}$. Moreover, according to the innumerous published results, the fracture mechanics approach has also been proven to be a very useful tool to gain insight this correlation. Lee et al. [9], for example, investigated experimentally the bond thickness-effect on the fracture toughness of compact tension (CT) adhesive/aluminium alloy joint specimens with five different bond thicknesses: $0.1,0.3,0.7,1.5$ and $2.1 \mathrm{~mm}$. Similar to [9], based on linear elastic fracture mechanics (LEFM), Yan et al. [10] have reported that the fracture toughness of doublecantilever-beams (DCB) specimens was affected by bond thickness. So far, the bond thicknesseffect can be best attributed based upon the constraint effect induced by the adherends, the statistical probability of imperfections or defects and the change of the energy dissipating mechanisms of the adhesive layer $[1,6]$. 
Other important factors which are crucial in evaluating the joints strength are the multiaxial stress conditions in the adhesive layer and the stress concentration at the vicinity of interface corner. Because of these two factors, strength and failure criteria of bulk adhesive can not be applied directly to estimate the failure stress of adhesive joints. Therefore, many researchers have investigated these features by adopting scarf joints with various scarf angles [3, 11, 12]. In a noteworthy study, Adams and Coppendale [13] reported that in the case of ductile epoxy adhesive, the stress triaxiality state causes not only to an increase in apparent adhesive layer modulus but also an increase in strength of butt joint. On the other hand, the existence of stress concentration reduces the failure stress of butt joint bonded with brittle epoxy adhesive.

In practical situation, as briefly introduced above, the most widely employed testing configurations to assess the strength of adhesive joints are butt joints, scarf joints, single or double lap joints and DCB joints. However, most of these investigations considered only adhesive joints bonded with similar adherend, so much so, the study on sandwiched dissimilar materials joints is hardly available thus motivated this work. It has been reported that, in terms of mechanical behavior and stress performance, the latter behaves slightly different if compared to the former due to the more complex elastic mismatches incorporated $[7,14,15]$.

The objectives of this study are twofold. First is to determine the relationship between the bond thickness and in situ mechanical properties of brittle epoxy adhesive in the scarf joints since there are very limited sources in the literature regarding this relationship. Second is to predict the strength of scarf joint with an appropriate failure criterion regardless of their scarf angle. Thus, in 
this study, failure test of epoxy adhesively-bonded scarf joints of dissimilar adherends was conducted under a remote tension load on several scarf angles and various adhesive bond thicknesses. The effect of joint geometry (i.e. bond thickness and scarf angle) upon the effective mechanical properties and strength of scarf joints will be presented and qualitatively discussed. In addition, the applicability of conventional failure criteria to the prediction of scarf joint strength is also addressed.

\section{Experimental procedures}

The epoxy adhesive resin used in this study was Hi-Super 30 produced by Cemedine Co., Japan. This is a commercial brittle epoxy adhesive which can be cured at room temperature approximately in 30 minutes. The adhesive was mixed thoroughly prior to bonding by mixing the epoxy resin and hardener with a centrifugal conditioning mixer (AR-100 from THINKY Co.) for 1 min: 3 min schedule of diffusion and de-foaming, respectively. The mechanical properties of the bulk epoxy adhesive have been reported in our previous study [16] wherein the cure state was at R.T. for over 24 hours. Figure 1 below shows the stress-strain responses of bulk epoxy adhesive specimens with its geometry and dimensions. It is noted from this figure that the bulk epoxy adhesive used in this study shows relatively linear stress-strain behavior and the fracture was also brittle in manner. The pertinent results are tabulated in Table 1 where, $E, \sigma_{\mathrm{y}}$ and $v$ are Young's modulus, $0.2 \%$ proof stress and Poisson's ratio, respectively. 
To obtain the strength and failure behavior of adhesive joints, scarf joint specimens were prepared and its configuration and dimensions are shown in Fig. 2. The adherends consisted of SUS304 stainless steel and YH75 aluminium alloy. Prior to bonding, bonding surfaces were uniformly polished with \# 2000 waterproof abrasive paper and afterward degreased with acetone. Target adhesive bond thickness, $d$ inside a scarf joint was controlled by using a specially developed fixture and varied between $0.1 \mathrm{~mm}$ and $1.2 \mathrm{~mm}$. Figure 3 shows the fixture used in controlling the bond thickness which has two micrometers at its both sides. All specimens were cured at R.T. over 24 hours. After specimens were totally cured, the excess adhesive was removed by a portable grinder. Figure 4 shows examples of photos of ground specimen edges. Obviously, fairly sharp edges were realized as can be seen from this figure. The actual bond thickness, $t$ was measured by a digital microscope and the value is given in Table 2. Then, four strain gages of $5 \mathrm{~mm}$ length (KFEL-5-120-C1L1M2R from Kyowa Electronic Instruments Co., Ltd.) were mounted on bonding line; two were perpendicular to the bonding line (i.e. front and back sides of specimen) and the other two in the longitudinal direction (i.e. left and right sides of specimen). Failure tensile tests of scarf joints specimens were carried out by a universal testing machine (INSTRON 4206). All specimens were tested at R.T. with the crosshead speed held constant at $0.5 \mathrm{~mm} / \mathrm{min}$.

\section{Evaluation of stresses and strains in scarf joints}

If scarf joints are submitted to the axial tensile load, stresses and strains inside the adhesive layer of scarf joints are relatively uniform except for the small region at the vicinity of interface 
corner. In this section, the discussion will be restricted only to the stresses and strains in the central region of adhesive layer in scarf joints. Figure 5 shows the coordinate system which is typically used to evaluate stresses and strains in the central region of adhesive layer in scarf joints [3]. Theoretically, for scarf joints loaded axially with average stress, $\sigma_{0}$, normal and shear stresses are given by:

$$
\sigma_{n}=\sigma_{0} \sin ^{2} \theta
$$

and

$$
\tau_{s n}=\sigma_{0} \sin \theta \cos \theta
$$

, respectively. Other stresses acting in s- and z-direction are identical:

$$
\sigma_{s}=\sigma_{z}=v_{a} \sigma_{n} /\left(1-v_{a}\right)
$$

According to these stresses, maximum and minimum principal stresses can be derived as:

$$
\sigma_{1,3}=\left\{\sigma_{s}+\sigma_{n} \pm \sqrt{\left(\sigma_{s}-\sigma_{n}\right)^{2}+4 \tau^{2}{ }_{s n}}\right\} / 2
$$

and median principal stress is obtained as follows:

$$
\sigma_{2}=\sigma_{s}=\sigma_{z}=v_{a} \sigma_{n} /\left(1-v_{a}\right)
$$

In addition, Mises equivalent stress is given by:

$$
\sigma_{e q}=\sqrt{\left(\sigma_{1}+\sigma_{3}\right)\left(v^{2}-v+1\right)-3 \sigma_{1} \sigma_{3}}
$$

and hydrostatic stress is given by:

$$
\sigma_{\text {hyd }}=\left(\sigma_{1}+\sigma_{2}+\sigma_{3}\right) / 3
$$

To evaluate the stresses and strains of scarf joint, 2D non-linear elastic FE analysis was also performed using ANSYS 11 code. The eight nodes isoparametric elements were used to construct 
the FE mesh. Only plane stress condition has been considered. The FE mesh in the adhesive layer region was refined sufficiently whereas the finest mesh size was $0.01 \mathrm{~mm}$ x $0.01 \mathrm{~mm}$. To constitute the adhesive layer in the FE model, the true stress-strain curve was extrapolated from the actual uniaxial tensile test data of specimen no. 3 as shown in Fig. 1. The adherends were assumed to remain elastic materials and the data of mechanical properties were taken from Table 1 . We employed internal multipoint constraint (abbreviated as MPC hereafter) approach to define the contact assembly in FE model of scarf joint. These MPC elements ignore any friction and the interaction between adhesive and adherend is always bonded (i.e. no separation at the interface). With this feature, the stress of each interface nodes can be obtained from its closest integration point. 2D-FE simulations were carried out to investigate the stress-y distribution along the joint interfaces, near the interface corner region and in the center of adhesive layer.

\section{Results and discussion}

\subsection{Mechanical properties of adhesive layer}

The representatives of load-displacement plots from tensile test of scarf joints are shown in

Figs. 6 (a) and (b). The load-displacement curves exhibit linear behavior until they reach the maximum load. After the maximum load, failure occurs suddenly. These features are comparable to the brittle nature of the adhesive itself. It is also clearly seen that the maximum load of scarf joints increases with the decreasing scarf angle and bond thickness. Figure 7 (a) below shows an example of stress-strain data obtained from $45^{\circ}$ scarf joint specimen in our experiment. As can be seen in this 
figure, there is difference between the two values. However, the difference between the two values always exist since the specimen is loaded by pins where a slight misalignment in the attachment of specimen to the pin will results in the eccentricity of loading. Nevertheless, the stress-strain relation of each gage is almost linear except for some cases where a small flexural was recorded at the early stage of loading. Therefore, if average of two values of opposite gages is taken, the data can be corrected then we may assume that the results can be considered acceptable. Figure 7 (b) shows an example of stress-strain relation obtained after averaging the two values of opposite gages. We can see in this figure that a linear stress-strain relation is obtained for each averaged data of each specimen. This is also true for all specimens tested. See Fig. 2 for the positioning of strain gages.

The apparent Young's modulus of adhesive layer, $E_{a d h}$ can be measured by dividing the normal stress, $\sigma_{\mathrm{n}}$ of scarf joints by the apparent strain of adhesive layer, $\varepsilon_{\text {adh }}$. Here, a correction is needed to deduce $\varepsilon_{\text {adh }}^{\prime}$ from the strain output obtained by strain gage, $\varepsilon_{\mathrm{g}}$. This can be fulfilled by calculating:

$$
\varepsilon_{a d h}^{\prime}=\frac{\varepsilon_{g}}{t}\left[L-\frac{1}{2}(L-t) \frac{\sigma}{E_{1}}-\frac{1}{2}(L-t) \frac{\sigma}{E_{2}}\right]
$$

where, $L$ is the length of strain gage and subscripts 1 and 2 are referred to the SUS304 and YH75, respectively. It has been established for relatively brittle adhesive, that $E^{\prime}{ }_{a d h}$ is related to the Young's modulus of bulk epoxy adhesive, $E_{a d h}$ by [1]

$$
E_{a d h}^{\prime}=\left[\frac{\left(1-v_{a d h}\right)}{\left(1+v_{a d h}\right)\left(1-2 v_{a d h}\right)}\right] \cdot E_{a d h}
$$

Thus, the effect of bond thickness on apparent Young's modulus of adhesive layer, $E_{\text {' }}$ adh is shown in Fig. 8. It is noted, by substituting Poisson's ratio of bulk epoxy adhesive, $v_{a d h}$ into Eq. 9, that $E_{\text {'adh }}$ is 
approximately 2 times higher than $E_{a d h}$ and this is also plotted in Fig. 8, together with the $E_{a d h}$. Clearly, $E_{a d h}$ is higher than $E_{a d h}$ and is found to be affected by the bond thickness of scarf joints wherein $E_{\text {adh }}{ }_{\text {is }}$ gradually increased when the bond thickness decreases. The apparent Young's modulus of adhesive layer in scarf joints is found to be $1.5 \sim 5$ times higher than those of bulk epoxy adhesive, which has been obtained from tensile tests. This also suggests that the apparent Poisson's ratio of adhesive layer, $v^{\prime}$ adh is not always equals to $v_{a d h}$ and changes with the bond thickness. By substituting $v_{a d h}$ in Eq. 9 with $v^{\prime}{ }_{a d h}$, the effect of bond thickness on apparent Poisson's ratio of adhesive layer, $v_{a d h}^{\prime}$ can be obtained as shown in Fig. 9. This figure confirms that for thick adhesive bond (i.e. $t>0.4 \mathrm{~mm}$ ), $v^{\prime}{ }_{a d h}$ is lower than $v_{a d h}$ and for thin adhesive bond (i.e. $t<0.4 \mathrm{~mm}$ ), $v^{\prime}{ }_{a d h}$ is greater than $v_{a d h}: v^{\prime}{ }_{a d h}$ varies across the bond thickness.

\subsection{Failure criteria of scarf joints}

Amongst others, the maximum principal stress and Mises equivalent stress are the most widely accepted as the appropriate failure criteria for scarf joints $[4,13,15]$. The former is for scarf joints of $45^{\circ}$ to $90^{\circ}$ while the latter is used for scarf joints with $0^{\circ}$ to $45^{\circ}$. Figure 10 shows the effect of scarf angle on the failure criteria of scarf joints. Clearly, for scarf joints with the scarf angle, $\theta$ larger than $45^{\circ}$, maximum principal stress is the dominant failure criterion. Though, for scarf joints with the scarf angle, $\theta$ smaller than $45^{\circ}$, Mises equivalent stress becomes the dominant failure criterion. However, the bond thickness effect upon these failure criteria is still need to be elucidated. 
The comparison between maximum principal stress and Mises equivalent stress obtained from experimental results is shown in Fig. 11. Here, the ratio of each criterion to the failure stress, $\sigma_{\mathrm{c}}$ is given. Obviously, the scatter of data obtained by Mises equivalent stress is greater than the maximum principal stress. Therefore, maximum principal stress is preferable than Mises equivalent stress and could be used to determine the failure of scarf joints with various bond thickness. However, attention should be paid when applying the maximum principal stress criteria because there is yet a tendency where $\sigma_{1}$ reduces with the increasing bond thickness as shown in Fig. 12 (a). Figure12 (b) again supports the inapplicability of Mises equivalent stress criterion where the scatter is comparatively worst.

Recently, Imanaka et al. [3] have evaluated the yield and failure criteria of scarf joints with $0.3 \mathrm{~mm}$ thickness adhesive layer based on stress multiaxiality parameter. In their study, they successfully estimated the endurance limits of various scarf joints with three different types of adhesive: unmodified, Thiokol-modified and rubber-modified adhesive. Since they only considered a constant adhesive thickness, the straightforward applicability of this approach to the present investigation is still in doubt. Hereafter, we will apply this approach and towards the end, verify its validity.

Principal stresses acting inside the adhesive layer of scarf joints can be measured experimentally from the strain gages. For this purpose, we employed the Rosette analysis to the measured strain values from the output of four strain gages. It is noted that, since strain in sdirection is negligible, only strains in n- and y-directions are taken into account. The average of two 
strain gages of opposite sides was taken. From strain values acting on both n- and y-directions, we can obtain the maximum and minimum principal strains as:

$$
\varepsilon_{1,3}=\left\{\varepsilon_{s}+\varepsilon_{g} \pm \sqrt{\varepsilon_{g}^{2}+\left(\varepsilon_{g}-2 \varepsilon_{y}\right)^{2}}\right\} / 2
$$

Thus, from Eq. 10, the principal stresses can be derived, respectively as what follows:

Maximum principal stress

$$
\sigma_{1}=\frac{E^{\prime}}{1-v^{\prime 2}}\left(\varepsilon_{1}+v^{\prime} \varepsilon_{3}\right)
$$

Median principal stress

$$
\sigma_{2}=\sigma_{z}=\frac{v^{\prime} E^{\prime}}{1-v^{\prime 2}} \varepsilon_{g}
$$

Minimum principal stress

$$
\sigma_{3}=\frac{E^{\prime}}{1-v^{\prime 2}}\left(\varepsilon_{3}+v^{\prime} \varepsilon_{1}\right)
$$

where, for plane strain condition, $E^{\prime}$ and $v^{\prime}$ are given, respectively by:

$$
\begin{aligned}
& E^{\prime}=\frac{E_{a d h}^{\prime}}{1-v_{a d h}^{\prime 2}} \\
& v^{\prime}=\frac{v_{a d h}^{\prime}}{1-v_{a d h}^{\prime}}
\end{aligned}
$$

Now we will verify the stress multiaxiality failure criterion. In this regard, stress multiaxiality can be expressed by one parameter, that is the ratio of the principal stresses; either $\sigma_{3} / \sigma_{1}$ or $\sigma_{2} / \sigma_{1}$. Fig. 13 shows the relation between $\sigma_{3} / \sigma_{1}$ and bond thickness, $t$. In this figure, we can confirm that the $\sigma_{3} / \sigma_{1}$ is almost constant irrespective of the scarf angle. This suggests the $\sigma_{3} / \sigma_{1}$ criterion satisfies one of the material constant regulations which must be independent of bond thickness. Nevertheless, the experimental results should also be compared with the theoretical prediction to verify the applicability of this criterion. 
The stress multiaxiality in the central region of adhesive layer in scarf joints of various angles is shown in Fig. 14. Here, the dash-dash lines are referred to the theoretical values obtained from Eq. 4 to Eq. 5. Obviously, for scarf joints considered (i.e. $\theta=45^{\circ}, 60^{\circ}$ and $75^{\circ}$ ) in this study, the stress states inside the adhesive layer are remarkably triaxial and the magnitude of tension principal stresses increases with the inclining scarf angle. However, it can be seen that the experimental results do not match with the theoretical values especially for $\theta=45^{\circ}$ and $60^{\circ}$ scarf joints tested. Hence, $\sigma_{3} / \sigma_{1}$ criterion also is not applicable to the results of the present study. The reason for this discrepancy will be explained in the subsequent section in terms of the failure behavior.

\subsection{Failure surfaces observation}

From failure surface examinations, the brittle failure was observed in all scarf joints specimens tested as shown in Fig. 15. Noteworthy, the bulk epoxy adhesive employed in this study also shows a very brittle manner when failed [16]. From Fig. 15, we can distinguish the failure path of adhesive layer in scarf joints as two types, as schematically shown in Fig. 16. It is seen that, in all cases, the failure initiates at the left steel/adhesive interface corner and propagates through the upper interface boundary up to some distance. After that, the crack deviates into the adhesive layer and immediately reaches the adjacent aluminium/adhesive interface. The difference between path A and $\mathrm{B}$ is that for path $\mathrm{A}$, the distance of initial interface boundary propagation is shorter than those 
in path B. Type of path for each specimen is summarized in Table 3. Moreover, it is noted that, path A is typically observed in the scarf joints of $45^{\circ}$ while for scarf joints of $75^{\circ}$ is path $\mathrm{B}$.

These observations can be explained with the help of FE stress analysis. For instance, the stress-y contour for scarf joint having $45^{\circ}$ scarf angle is shown in Fig. 17. From this FE stress-y contour, it is revealed that the highest stress-y exists at the left interface corner of steel/adhesive. It is also noticed that, at a distance ahead of the steel/adhesive interface line, the stress concentration is gradually vanished while at the aluminium/adhesive interface it is proportionally increased, thus the failure path deviates from steel/adhesive interface to the opposite aluminium/adhesive interface as observed in failure path. Nevertheless, there is no significant change in the failure load recorded between scarf joints failed with path A and path B. Thus, the difference between path $\mathrm{A}$ and path $\mathrm{B}$ is maybe related to the adhesive force and/or surface property which are up to now is still difficult to evaluate and less understood.

The most important finding in these failure surfaces and path trajectories examination as well as stress-y distribution in the FE results is that the failure has great potential to be initiated at an identical spot which is the interface corner of steel/adhesive. This is probably why neither the maximum principal stress criterion nor $\sigma_{3} / \sigma_{1}$ criterion can precisely estimate the strength and failure behavior of scarf joints; these failure criteria will be applicable only if failure occurs within the adhesive layer (i.e. cohesive failure). Thus, we need another criterion which best estimates the relationship between bond thickness and failure stress of scarf joints bonded with brittle epoxy adhesive. 


\subsection{Hc parameter based strength prediction of scarf joints}

Most recently, much attention has been paid to the validation of interface corner failure criterion which is analogous to the LEFM concept [12, 17-20]. It is well known that when adhesive joint is subjected to a remote uniaxial load, within linear elasticity context, the asymptotic stress field develops at the vicinity of interface corners and exhibits singularity behavior of formø $\mathrm{Hr}^{-\lambda}$ [21], where $\sigma$ is the stress, $r$ is distance from the interface corner, $H$ is the intensity of stress singularity and $\lambda$ is the order of stress singularity. Instead of the crack, $H$ is associated with the discontinuity at the interface corner. Failure is assumed to initiate at the interface corner when $H$ attains a critical value, Hc. In order to be a valid failure criterion, the extent of any plastic zone or deformation at the interface corner must be entirely embedded within the region dominated by the Hc. There are already some experimental evidences, which emphasized that $H c$ and $\lambda$ parameters can be effectively used to successfully predict the onset of failure as well as to eventually establish the relationship between bond thickness and strength of certain adhesively-bonded butt and scarf joints [12, 17-19]. Consequently, the evaluation of $\lambda$ in such adhesive joints is of practical important, and this can be done via following the lengthy calculation procedure as performed by Bogy [22]. Refer to Appendix for details.

Following the same procedure as Bogy as mentioned above, assuming the plane strain condition, we have measured the $\lambda$ of scarf joints under present consideration and the results are plotted in Fig. 18. As can be seen, $\lambda$ at an interface corner varies with the scarf angle and vanishes at 
a certain scarf angle. From these results, at a glance, one can anticipate at which interface corner the scarf joint will fail. For example, at $45^{\circ}$ scarf angle, $\lambda$ exists at steel/adhesive interface corner but not at aluminium/adhesive interface corner. So, in this case, it can be predicted that the failure will always initiate at steel/adhesive interface corner. In fact, it has been confirmed from the failure surface observations that failure initiates at this point in almost all specimens tested as already mentioned above. Figure 19 shows the failure stress against bond thickness, $t$ for scarf joints having various scarf angles. As can be seen, failure stress of scarf joints increases with the decreasing bond thickness, $t$ irrespective of scarf angle. To predict the strength of adhesive joints and its relation to bond thickness, the interface corner toughness, $H c$ approach is now applied. According to Akisanya and Meng [20], Hc is defined by:

$$
H c=\sigma_{c} t^{\lambda} Q(\alpha, \beta)
$$

where $Q$ is a non-dimensional constant function of the material elastic parameters (i.e. $\alpha, \beta$ are the Dunder's bimaterial constants). For simplicity, the value of $Q$ is taken as 0.5 . The values of $\lambda$ and average values of $H c$ (i.e. $\hat{H} c$ ) as well as standard deviation for scarf joints having scarf angle of $45^{\circ}$, $60^{\circ}$ and $75^{\circ}$ are summarized in Table 4 . It is noted that the ratio of standard deviation to $\hat{H} c$ is moderate, i.e. less than $30 \%$. This suggests that $H c$ is indeed a material property which is independent of bond thickness. Using the value of $\hat{H} c$ in conjunction with Eq. 16, inversely, the strength for each scarf joint can be predicted. Prediction lines for scarf joints having $45^{\circ}, 60^{\circ}, 75^{\circ}$ and $90^{\circ}$ are represented by long dash line, short dash line, dash-dot line and dot-dot line, respectively, as shown in Fig. 19. Note that the data for butt joints (i.e. $\theta=90^{\circ}$ ) are taken from our 
previously published results [7]. Obviously, to some extent, the prediction is in good agreement with the measured data. Hence, it is concluded that the application of $H c$ approach is appropriate to the estimation of the strength of brittle epoxy adhesively bonded scarf joints with several bond thicknesses.

\section{Conclusions}

In the present work, we have investigated both experimentally and analytically as well as numerically the effects of bond thickness and scarf angle upon the strength of scarf joints of dissimilar adherends bonded with a brittle epoxy adhesive. The following conclusions can be drawn:

1. The in situ mechanical properties of epoxy adhesive layer in scarf joints are found to be different from those of bulk epoxy adhesive. It is found that the apparent Young's modulus and apparent Poisson's ratio of epoxy adhesive layer are affected by the bond thickness.

2. Three existing failure criteria (i.e. the maximum principal stress, Mises equivalent stress and stress multiaxiality) have been employed to predict the relationship between bond thickness and joint strength. However, the results are not very satisfactory.

3. From analytical solutions, stress singularity, $\lambda$ exists most pronouncedly at steel/adhesive interface corner of joint having $45^{\circ}$ to $75^{\circ}$ scarf angle and this is in accordance with the FE analysis results and is also confirmed by failure surface observations wherein the failure has always initiated at this point. 
4. The strength prediction of brittle epoxy adhesively bonded scarf joints based on the interface corner toughness, Hc parameter is in good agreement with the experimentally measured data.

\section{References}

[1] Kinloch AJ. Adhesion and Adhesives: Science and Technology. London: Chapman and Hall; 1987.

[2] Wang CH, Rose LRF. Determination of triaxial stresses in bonded joints. International Journal of Adhesion \& Adhesives. 1997;17:17-25.

[3] Imanaka M, Fujinami A, Suzuki Y. Fracture and yield behavior of adhesively bonded joints under triaxial stress conditions. Journal of Materials Science. 2000;35:2481-91.

[4] Zhu Y, Kedward K. Methods of analysis and failure predictions for adhesively bonded joints of uniform and variable bondline thickness. U.S. Department of Transportation; 2005.

[5] Taib AA, Boukhili R, Achiou S, Gordon S, Boukehili H. Bonded joints with composite adherends. Part I. Effect of specimen configuration, adhesive thickness, spew fillet and adherend stiffness on fracture. International Journal of Adhesion \& Adhesives. 2006;26:226-36.

[6] Davies P, Sohier L, Cognard JY, Bourmaud A, Choqueuse D, Rinnert E, et al. Influence of adhesive bond line thickness on joint strength. International Journal of Adhesion \& Adhesives. 2009;29:724-36. 
[7] Afendi M, Teramoto T. Effect of bond thickness on fracture behavior of interfacial crack in adhesive joint of dissimilar materials. Journal of The Adhesion Society of Japan. 2009;45:471-6.

[8] Park J-H, Choi J-H, Kweon J-H. Evaluating the strengths of thick aluminum-to-aluminum joints with different adhesive lengths and thicknesses. Composite Structures. 2010;92:2226-35.

[9] Lee DB, Ikeda T, Miyazaki N, Choi NS. Damage zone around crack tip and fracture toughness of rubber-modified epoxy resin under mixed-mode conditions. Engineering Fracture Mechanics. 2002;69:1363-75.

[10] Yan C. Effects of substrate materials on fracture toughness measurement in adhesive joints. International Journal of Mechanical Sciences. 2001;43:2091-102.

[11] Bascom WD, Oroshnik J. Effect of bond angle on mixed-mode adhesive fracture. Journal of Materials Science. 1978;13:1411-8.

[12] Qian ZQ, Akisanya AR. An investigation of the stress singularity near the free edge of scarf joints. Euro J Mech. 1999;18:443-63.

[13] Adams RD, Coppendale J. The stress-strain behaviour of axially-loaded butt joints. Journal of Adhesion. 1979;10:49-62.

[14] Afendi M, Teramoto T. Fracture toughness test of epoxy adhesive dissimilar joint with various adhesive thicknesses. Journal of Solid Mechanics and Materials Engineering (JSME). 2010;4:9991010. 
[15] He D, Sawa T, Karami A. Stress analysis and strength evaluation of scarf adhesive joints with dissimilar adherends subjected to static tensile loadings. Journal of Solid Mechanics and Materials Engineering (JSME). 2009;3:1033-44.

[16] Afendi M, Teramoto T. Three-point bending fracture test of epoxy adhesive-bonded dissimilar materials. 14th JSME Kanto Meeting: JSME; 2008. p. 369-70.

[17] ReedyJr ED, Guess TR. Interface corner stress states: plasticity effects. International Journal of Fracture. 1996;81:269-82.

[18] Reedy ED, Guess TR. Interface corner failure analysis of joint strength: effect of adherend stiffness. International Journal of Fracture. 1997;88:305-14.

[19] Hattori T. A stress-singularity-parameter approach for evaluating the adhesive strength of single-lap joints. JSME International Journal. 1991;34.

[20] Akisanya AR, Meng CS. Initiation of fracture at the interface corner of bi-material joints. Journal of the Mechanics and Physics of Solids. 2003;51:27-46.

[21] Reedy Jr. ED. Strength of butt and sharp-cornered joints. In: Dillard DA, Pocius AV, editors. The Mechanics of Adhesion. 1 ed: Elsevier; 2002.

[22] Bogy DB. Two edge-bonded elastic wedges on different materials and wedge angles under surface tractions. Transactions of ASME, Journal of Applied Mechanics. 1971;38:377-86. 


\section{Appendix}

For two bonded elastic materials, Dunder's bimaterial mismatch constants in plane stress

condition are expressed by:

$$
\alpha=\frac{\left(1-v_{2}\right) / \mu_{2}-\left(1-v_{1}\right) / \mu_{1}}{\left(1-v_{2}\right) / \mu_{2}+\left(1-v_{1}\right) / \mu_{1}} \text { and } \beta=\frac{1}{2} \frac{\left(1-2 v_{2}\right) / \mu_{2}-\left(1-2 v_{1}\right) / \mu_{1}}{\left(1-v_{2}\right) / \mu_{2}+\left(1-v_{1}\right) / \mu_{1}}
$$

where, $v$ and $\mu$ are the material Poisson's ratios and shear modulus, respectively. Subscripts 1 and 2 refer to material 1 and material 2, respectively. The order of stress singularity, $\lambda$ for these materials combination can be calculated by solving the Bogy's characteristic equation as follows:

$$
A \beta^{2}+2 B \alpha \beta+C \alpha^{2}+2 D \beta+2 E \alpha+F=0
$$

here, the coefficients of $A$ through $F$ are written as follows:

$$
\begin{aligned}
& A=4 H\left(p, \theta_{1}\right) \cdot H\left(p, \theta_{2}\right) \\
& B=2 p^{2} \cdot \sin ^{2}\left(\theta_{1}\right) \cdot H\left(p, \theta_{2}\right)+2 p^{2} \cdot \sin ^{2}\left(\theta_{2}\right) \cdot H\left(p, \theta_{1}\right) \\
& C=4 p^{2} \cdot\left(p^{2}-1\right) \cdot \sin ^{2}\left(\theta_{1}\right) \sin ^{2}\left(\theta_{2}\right)+H\left\{p,\left(\theta_{2}-\theta_{1}\right)\right\} \\
& D=2 p^{2} \cdot\left\{\sin ^{2}\left(\theta_{2}\right) \cdot \sin ^{2}\left(p \theta_{1}\right)-\sin ^{2}\left(\theta_{1}\right) \cdot \sin ^{2}\left(p \theta_{2}\right)\right\} \\
& E=-D+H\left(p, \theta_{2}\right) \\
& F=H\left\{p,\left(\theta_{1}+\theta_{2}\right)\right\}
\end{aligned}
$$

$\theta$ is the bimaterial corner angle. $H$ function above is an auxiliary function which is defined as

$$
H(p, \theta)=\sin ^{2}(p, \theta)-p^{2} \sin ^{2}(\theta)
$$

The roots of this characteristic equation are related to $\lambda$ by

$$
\lambda=1-p
$$

There are few analytical methods available that could be used to solve Bogy's characteristics equation to obtain $\lambda$, e.g. Secant Method, Newton's method and Bisection method. In this study, we 
employed Bisection method for its simplicity. Only one root is of practical interest and this root is a real number (i.e. $0<\lambda<1$ ). The accuracy level of the analysis is set to $10^{-5}$. 


\section{List of Tables}

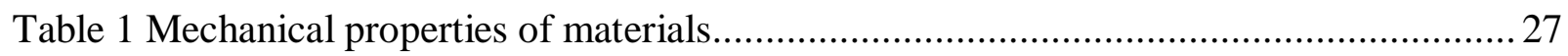

Table 2 Measured bond thickness, $t$ of scarf joints specimens .......................................... 27

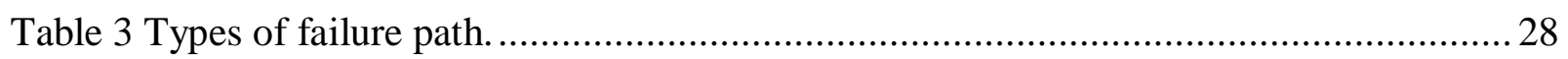

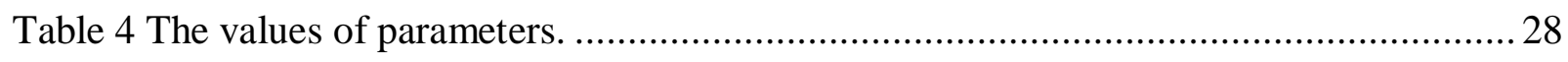




\section{List of Figures}

Fig. 1 Tensile stress-strain responses of bulk epoxy adhesive.

Fig. 2 Geometry of scarf joint.

Fig. 3 Fixture used in bonding and controlling the bond thickness of scarf joint specimens. 31

Fig. 4 Photos of ground specimen edges.

Fig. 5 Coordinate system of scarf joint. 33

Fig. 6 Load-displacement plots of scarf joint specimens having (a) $0.1 \mathrm{~mm}$ bond thickness and (b) $1.0 \mathrm{~mm}$ bond thickness.

Fig. 7 Stress-strain relations of $45^{\circ}$ scarf joint specimen having $0.1 \mathrm{~mm}$ and $1.0 \mathrm{~mm}$ bond

thicknesses.

Fig. 8 Effect of bond thickness on apparent Young's modulus of adhesive layer

Fig. 9 Effect of bond thickness on apparent Poisson's ratio of adhesive layer.

Fig. 10 Effect of scarf angle on failure criteria. 38

Fig. 11 Comparison between two failure criteria. 39

Fig. 12 Failure criterion against bond thickness 40

Fig. 13 Stress multiaxiality parameter against bond thickness.

Fig. 14 Stress multiaxiality of epoxy adhesive layer in scarf joints 42

Fig. 15 Failure surface of adhesive layer in scarf joints.

Fig. 16 Schematic of failure paths of adhesive layer in scarf joints. 44

Fig. 17 Stress-y contour in scarf joints having $45^{\circ}$ scarf angle. 
Fig. 18 Order of stress singularity, $\lambda$ at interface corner.

Fig. 19 Failure stress of scarf joints against bond thickness and prediction curves based on

Hc parameter. 
Table 1 Mechanical properties of materials

\begin{tabular}{|c|c|c|c|}
\hline Material & $E(\mathrm{GPa})$ & $\sigma_{\mathrm{y}}(\mathrm{MPa})$ & $v$ \\
\hline \hline Epoxy & 3.4 & $34.76[1.67]$ & 0.396 \\
\hline SUS304* & 206 & $307.8[6.02]$ & 0.3 \\
\hline YH75 (Al-alloy)* $^{*}$ & 7.1 & $559.0[7.82]$ & 0.33 \\
\hline
\end{tabular}

*Data taken from manufacturer's catalogue.

[ ] denotes value of standard deviation.

Table 2 Measured bond thickness, $t$ of scarf joints specimens

\begin{tabular}{|c|c|c|c|c|}
\hline \multirow{2}{*}{$\begin{array}{c}\text { Scarf angle, } \\
\theta\end{array}$} & \multirow{2}{*}{$\begin{array}{c}\text { Target bond } \\
\text { thickness, } d(\mathrm{~mm})\end{array}$} & \multicolumn{3}{|c|}{$t(\mathrm{~mm})$} \\
\hline & & Center ${ }^{\top}$ & Edge & Average \\
\hline \multirow{10}{*}{$45^{\circ}$} & 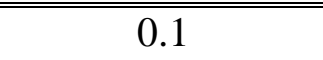 & 0.128 & $\begin{array}{c}0.174 \\
\end{array}$ & 0.151 \\
\hline & 0.2 & 0.246 & 0.269 & 0.267 \\
\hline & 0.3 & 0.351 & 0.378 & 0.365 \\
\hline & 0.4 & 0.469 & 0.469 & 0.469 \\
\hline & 0.5 & 0.564 & 0.557 & 0.561 \\
\hline & 0.6 & 0.664 & 0.691 & 0.668 \\
\hline & 0.7 & 0.741 & 0.763 & 0.752 \\
\hline & 0.8 & 0.800 & 0.837 & 0.819 \\
\hline & 0.9 & 0.959 & 0.973 & 0.966 \\
\hline & 1.0 & 1.029 & 1.136 & 1.083 \\
\hline \multirow{10}{*}{$60^{\circ}$} & 0.1 & 0.144 & 0.170 & 0.157 \\
\hline & 0.2 & 0.324 & 0.342 & 0.333 \\
\hline & 0.3 & 0.373 & 0.372 & 0.373 \\
\hline & 0.4 & 0.524 & 0.562 & 0.543 \\
\hline & 0.5 & 0.582 & 0.621 & 0.602 \\
\hline & 0.6 & 0.660 & 0.733 & 0.697 \\
\hline & 0.7 & 0.750 & 0.785 & 0.768 \\
\hline & 0.8 & 0.824 & 0.874 & 0.849 \\
\hline & 0.9 & 0.975 & 0.980 & 0.978 \\
\hline & 1.0 & 1.097 & 1.095 & 1.096 \\
\hline \multirow{10}{*}{$75^{\circ}$} & 0.1 & 0.127 & 0.148 & 0.138 \\
\hline & 0.2 & 0.258 & 0.289 & 0.274 \\
\hline & 0.3 & 0.330 & 0.371 & 0.351 \\
\hline & 0.4 & 0.443 & 0.473 & 0.458 \\
\hline & 0.5 & 0.532 & 0.555 & 0.544 \\
\hline & 0.6 & 0.646 & 0.676 & 0.661 \\
\hline & 0.7 & 0.736 & 0.786 & 0.761 \\
\hline & 0.8 & 0.844 & 0.923 & 0.884 \\
\hline & 0.9 & 0.931 & 0.976 & 0.934 \\
\hline & 1.0 & 1.029 & 1.070 & 1.049 \\
\hline
\end{tabular}

" represents the averaged value of two measurements. 
Table 3 Types of failure path.

\begin{tabular}{|c|c|c|c|c|}
\hline Specimen & $\begin{array}{c}\text { Target bond } \\
\text { thickness, } d(\mathrm{~mm})\end{array}$ & $4^{\circ}$ & $60^{\circ}$ & $75^{\circ}$ \\
\hline \hline 1 & 0.1 & $\mathrm{~A}$ & $\mathrm{~A}$ & $\mathrm{~A}$ \\
\hline 2 & 0.2 & $\mathrm{~A}$ & $\mathrm{~A}$ & $\mathrm{~A}$ \\
\hline 3 & 0.3 & $\mathrm{~A}$ & $\mathrm{~A}$ & $\mathrm{~B}$ \\
\hline 4 & 0.4 & $\mathrm{~A}$ & $\mathrm{~B}$ & $\mathrm{~B}$ \\
\hline 5 & 0.5 & $\mathrm{~B}$ & $\mathrm{~A}$ & $\mathrm{~A}$ \\
\hline 6 & 0.6 & $\mathrm{~B}$ & $\mathrm{~B}$ & $\mathrm{~B}$ \\
\hline 7 & 0.7 & $\mathrm{~A}$ & $\mathrm{~A}$ & $\mathrm{~B}$ \\
\hline 8 & 0.8 & $\mathrm{~B}$ & $\mathrm{~B}$ & $\mathrm{~B}$ \\
\hline 9 & 0.9 & $\mathrm{~A}$ & $\mathrm{~A}$ & $\mathrm{~B}$ \\
\hline 10 & 1.0 & $\mathrm{~A}$ & $\mathrm{~B}$ & $\mathrm{~A}$ \\
\hline
\end{tabular}

Table 4 The values of parameters.

\begin{tabular}{|c|c|c|c|c|}
\hline $\begin{array}{c}\text { Scarf angle, } \\
\theta\end{array}$ & $\overline{\lambda \lambda}$ & $\hat{H} c$ & Std Dev & Std Dev / $\hat{H} c(\%)$ \\
\hline $45^{\circ}$ & 0.279 & 8.137 & 2.131 & 26.18 \\
\hline $60^{\circ}$ & 0.362 & 5.482 & 1.328 & 17.27 \\
\hline $75^{\circ}$ & 0.365 & 4.818 & 0.832 & 24.23 \\
\hline $90^{\circ}[7]$ & 0.329 & 4.155 & 0.876 & 21.08 \\
\hline
\end{tabular}




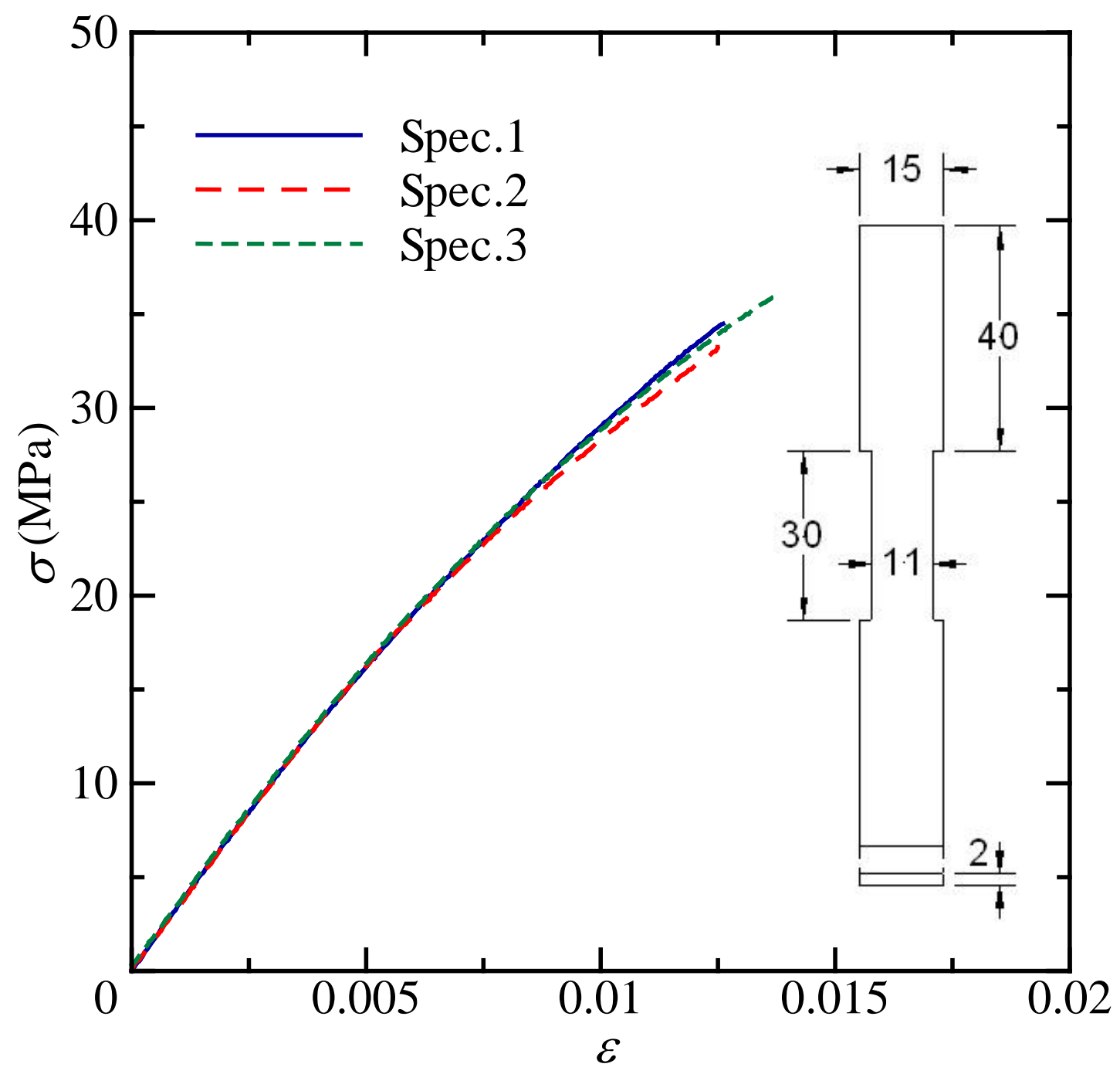

Fig. 1 Tensile stress-strain responses of bulk epoxy adhesive. 


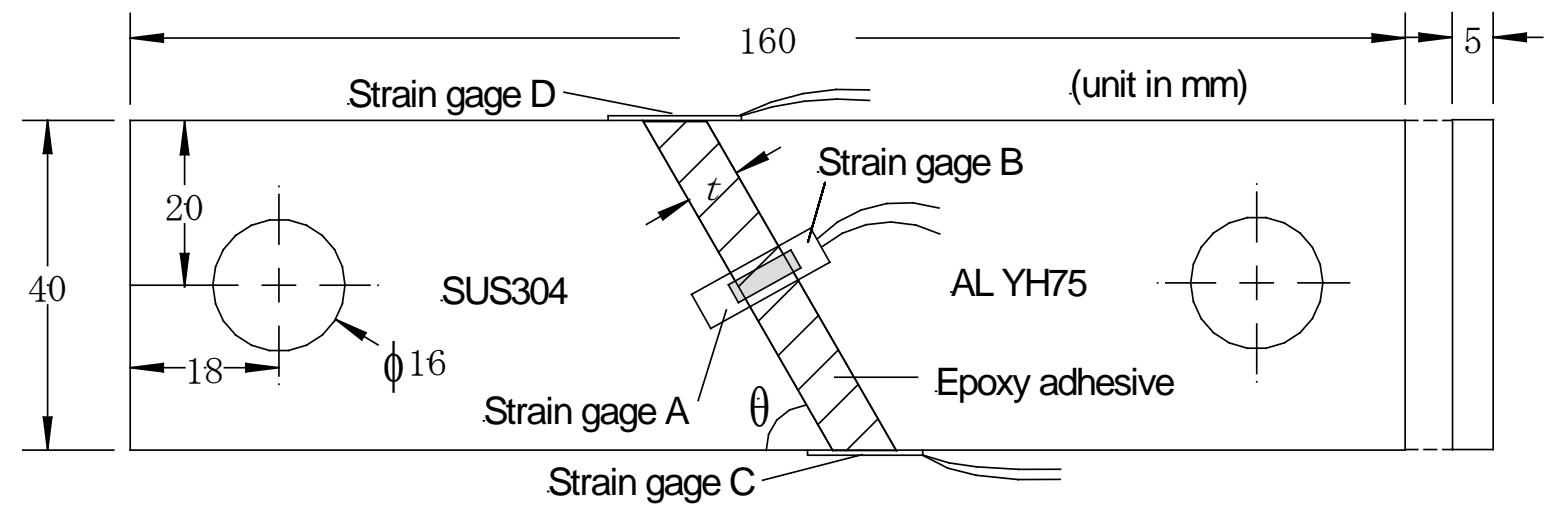

Fig. 2 Geometry of scarf joint. 


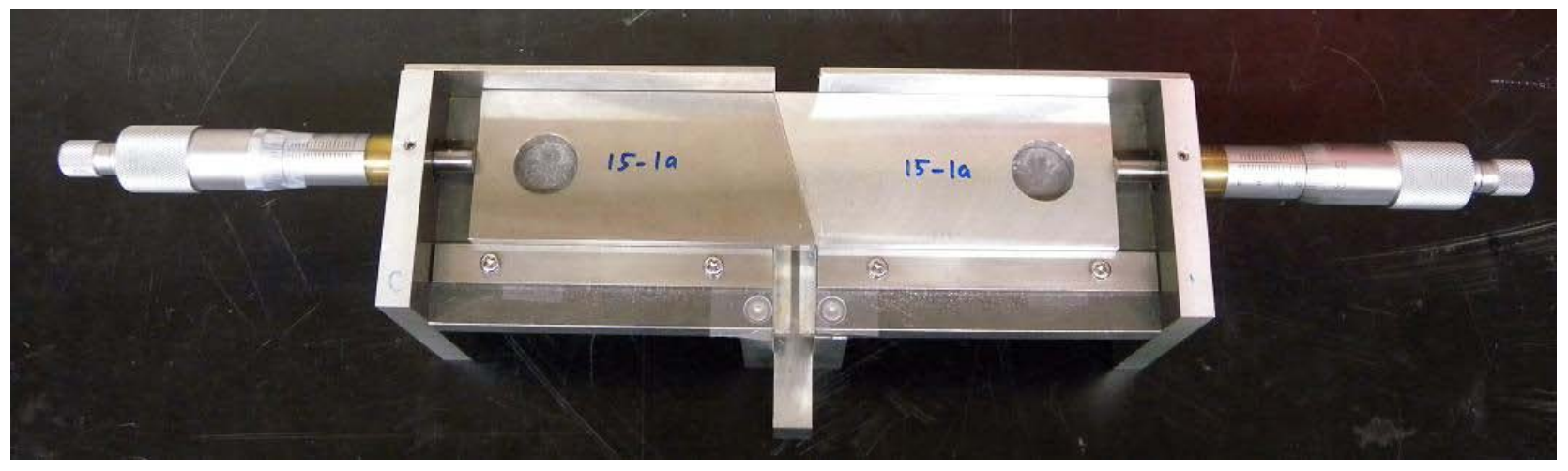

Fig. 3 Fixture used in bonding and controlling the bond thickness of scarf joint specimens. 


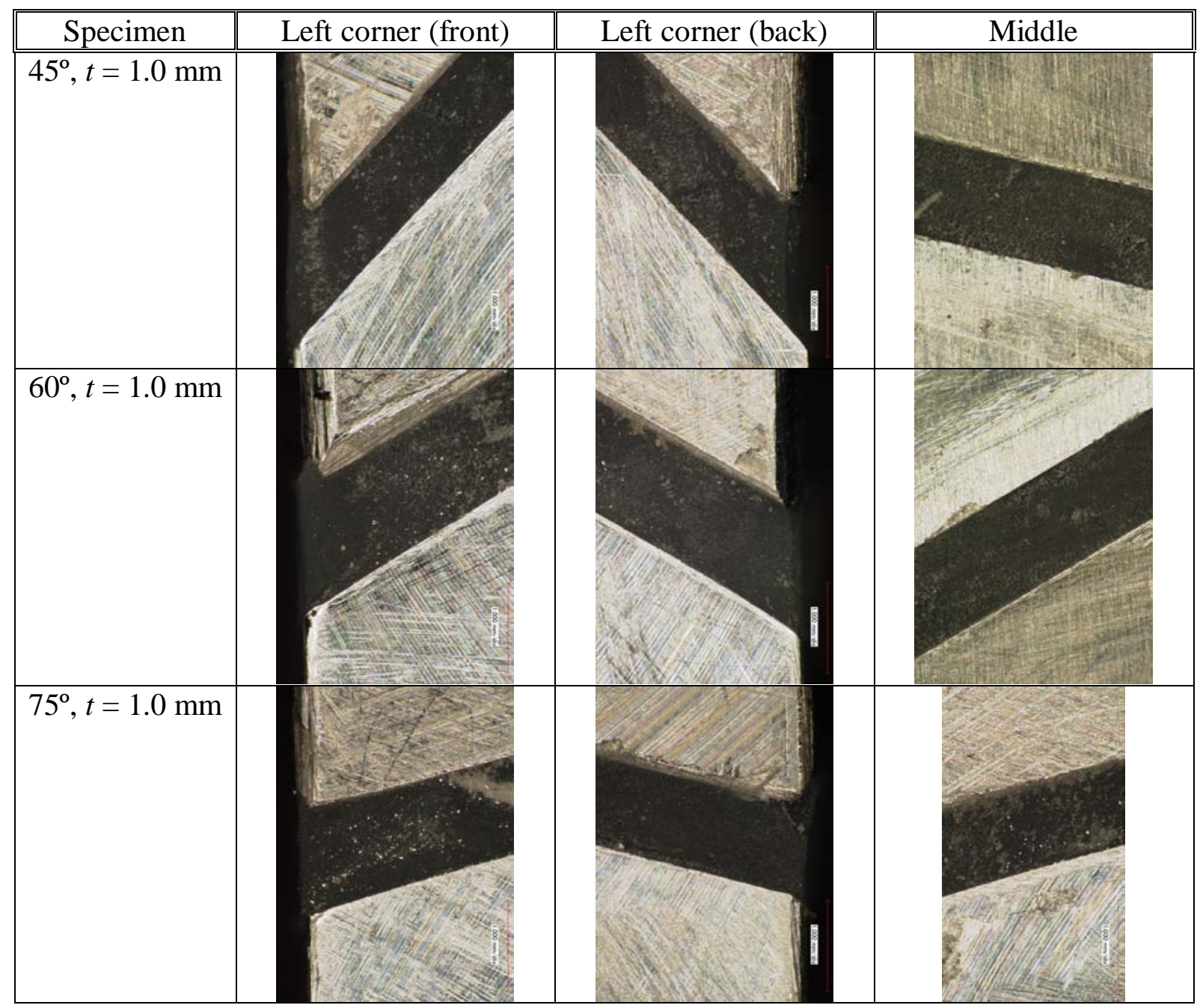

Fig. 4 Photos of ground specimen edges. 


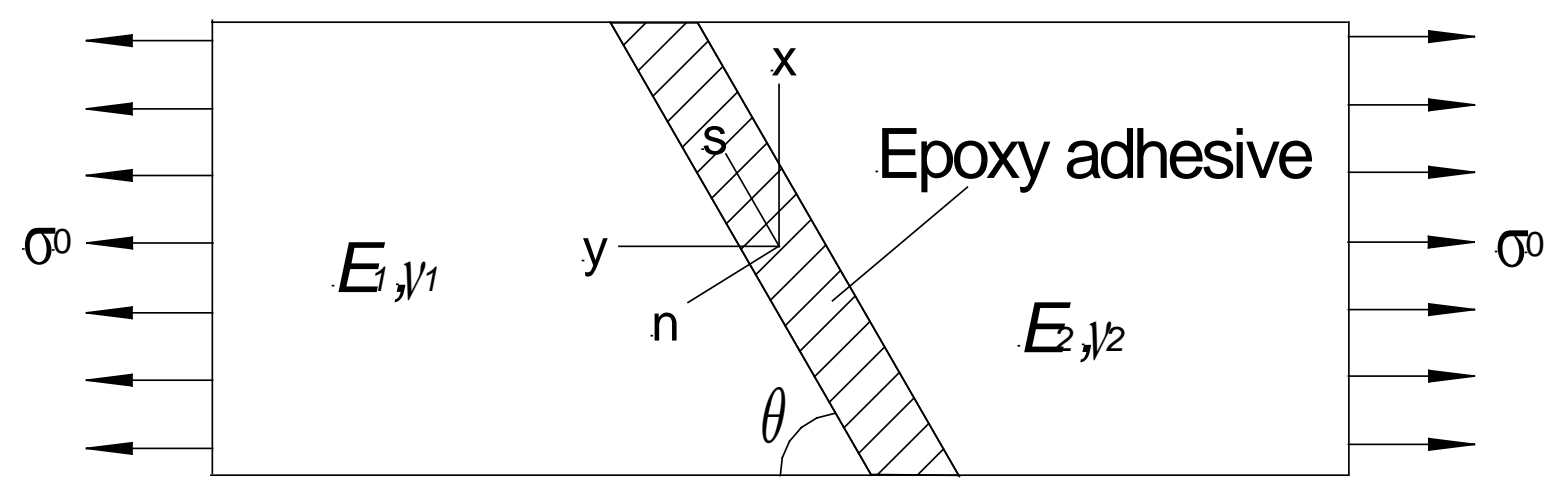

Fig. 5 Coordinate system of scarf joint. 


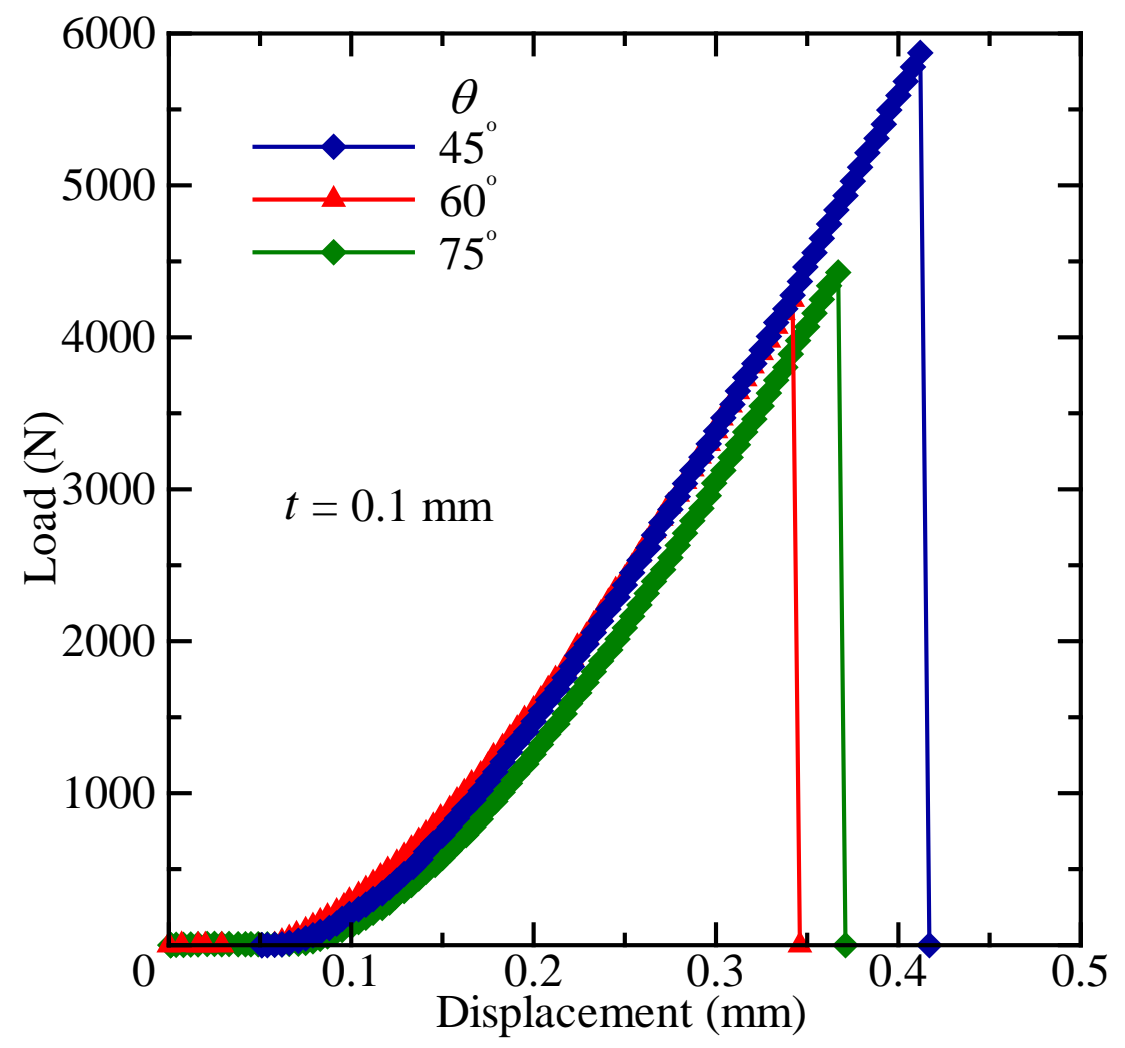

(a)

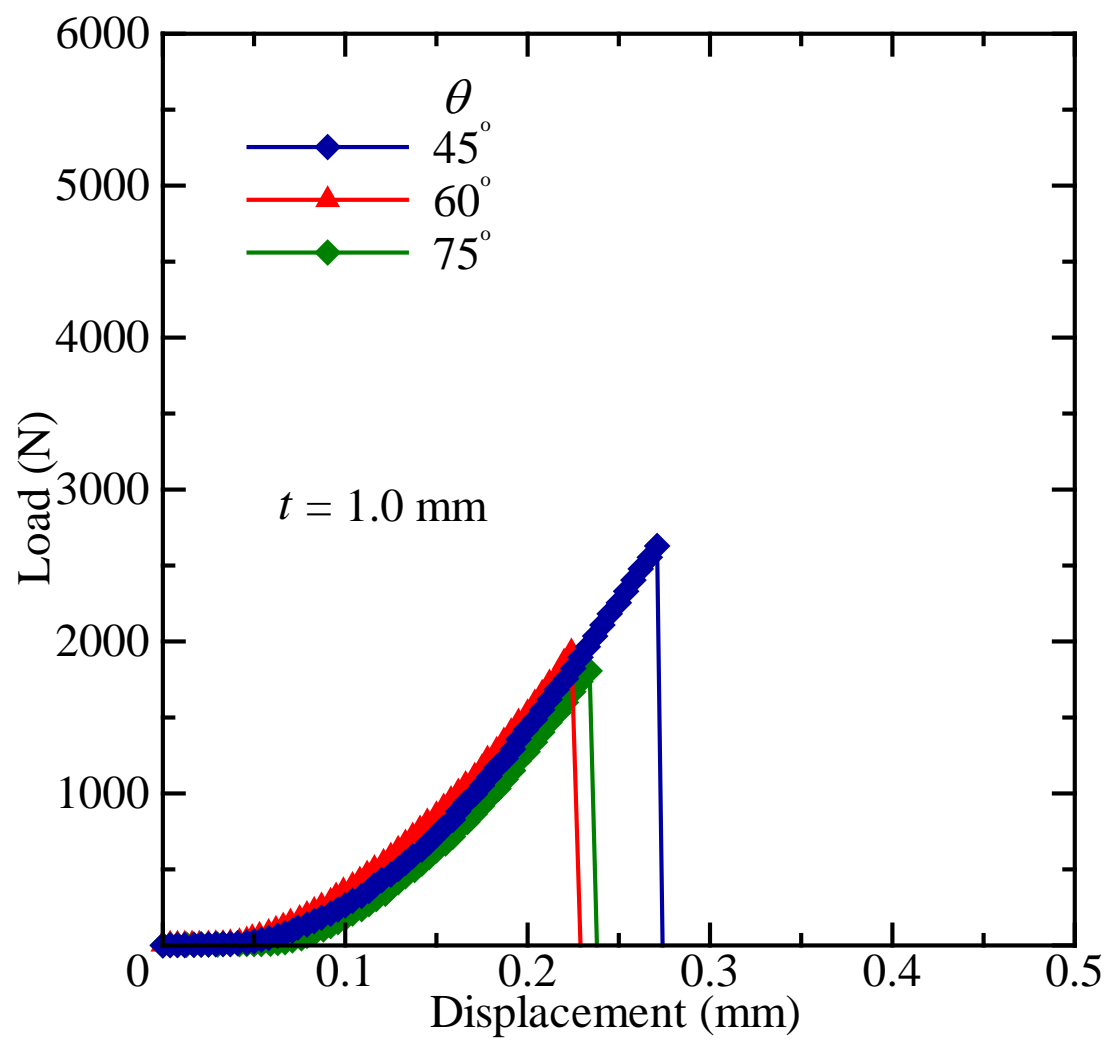

(b)

Fig. 6 Load-displacement plots of scarf joint specimens having (a) $0.1 \mathrm{~mm}$ bond thickness and (b) $1.0 \mathrm{~mm}$ bond thickness. 


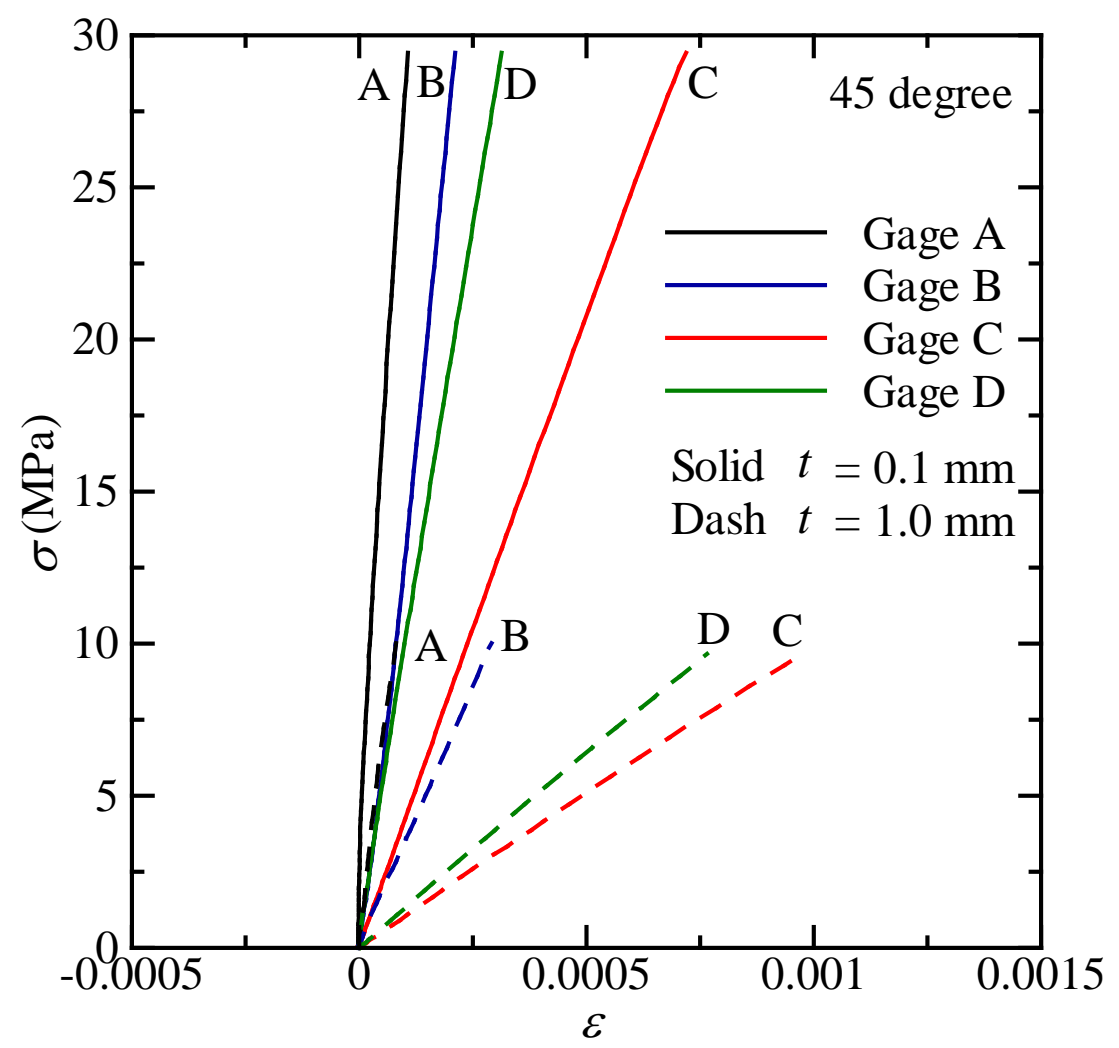

(a) Strain outputs measured from four gages.

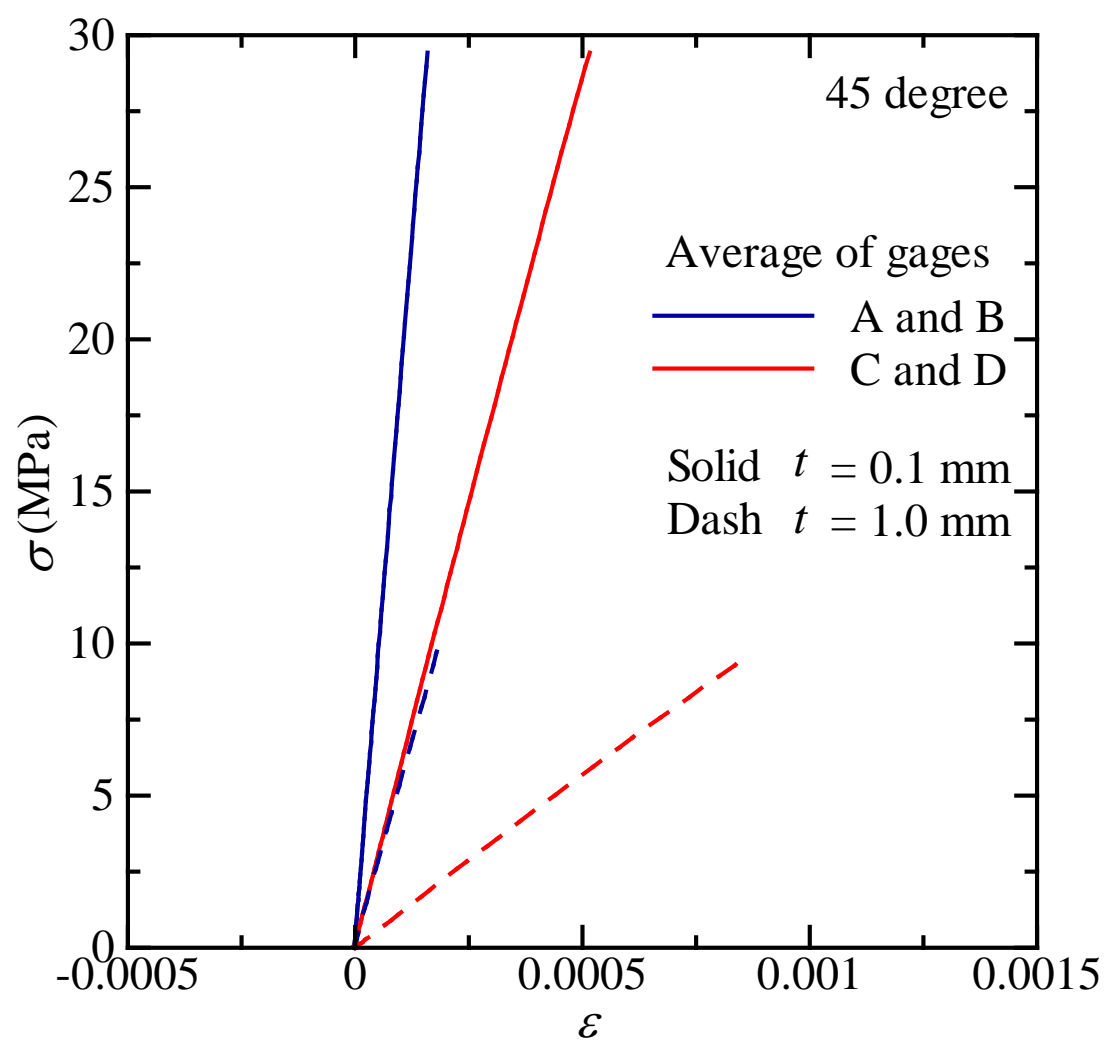

(b) After averaging the measurements of the opposite sides of the specimen.

Fig. 7 Stress-strain relations of $45^{\circ}$ scarf joint specimen having $0.1 \mathrm{~mm}$ and $1.0 \mathrm{~mm}$ bond thicknesses. 


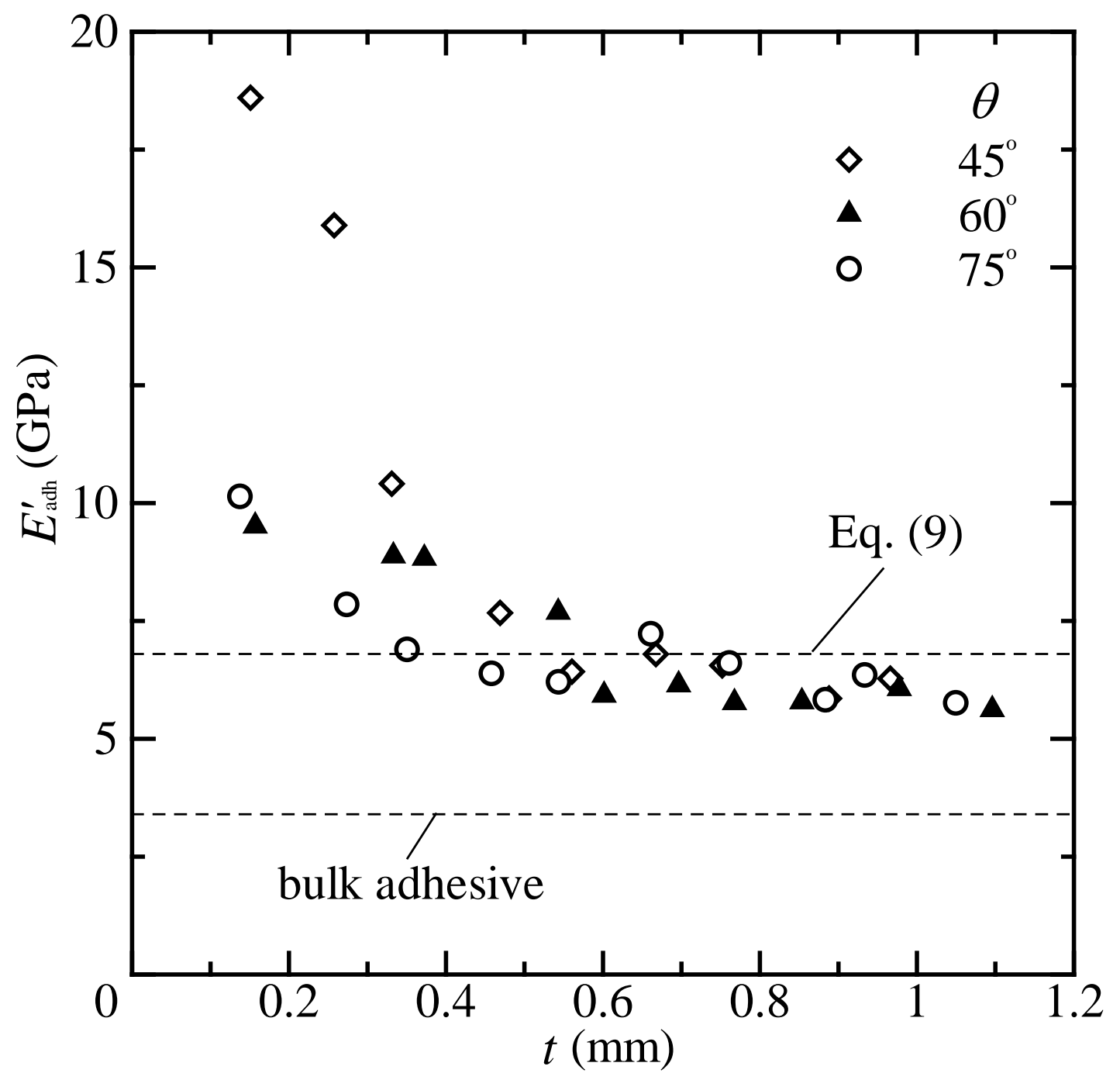

Fig. 8 Effect of bond thickness on apparent Young's modulus of adhesive layer. 


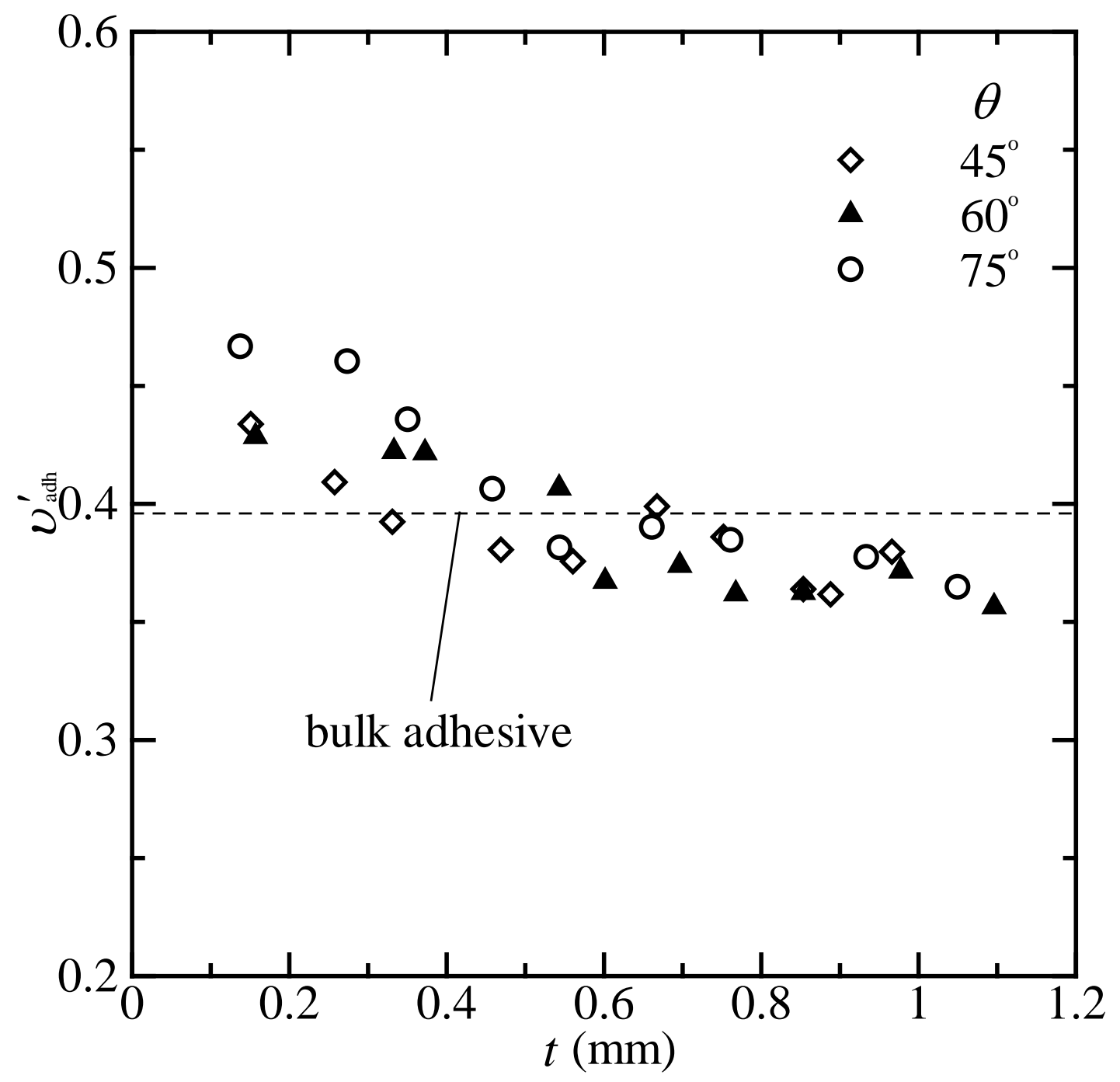

Fig. 9 Effect of bond thickness on apparent Poisson's ratio of adhesive layer. 


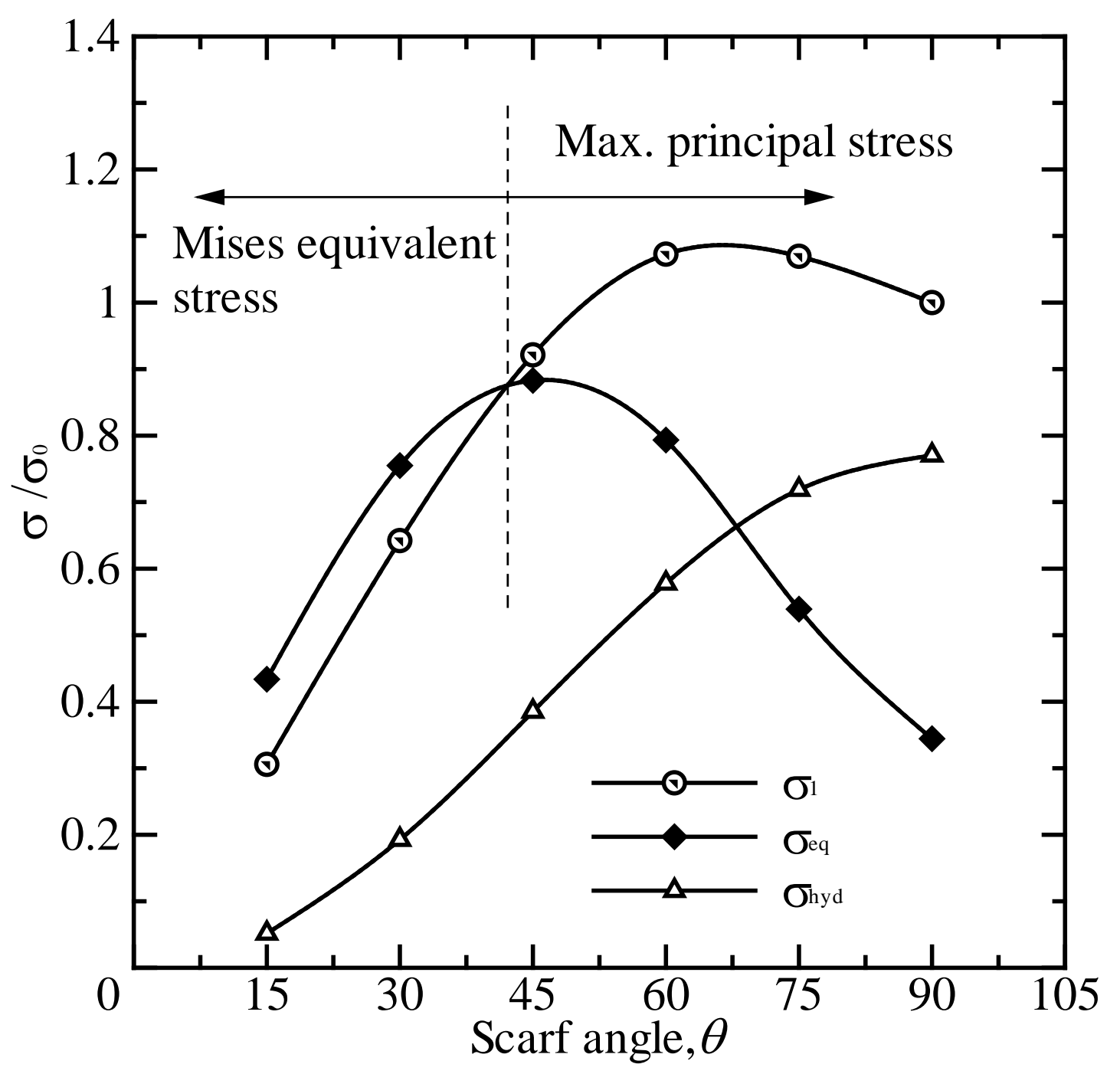

Fig. 10 Effect of scarf angle on failure criteria. 


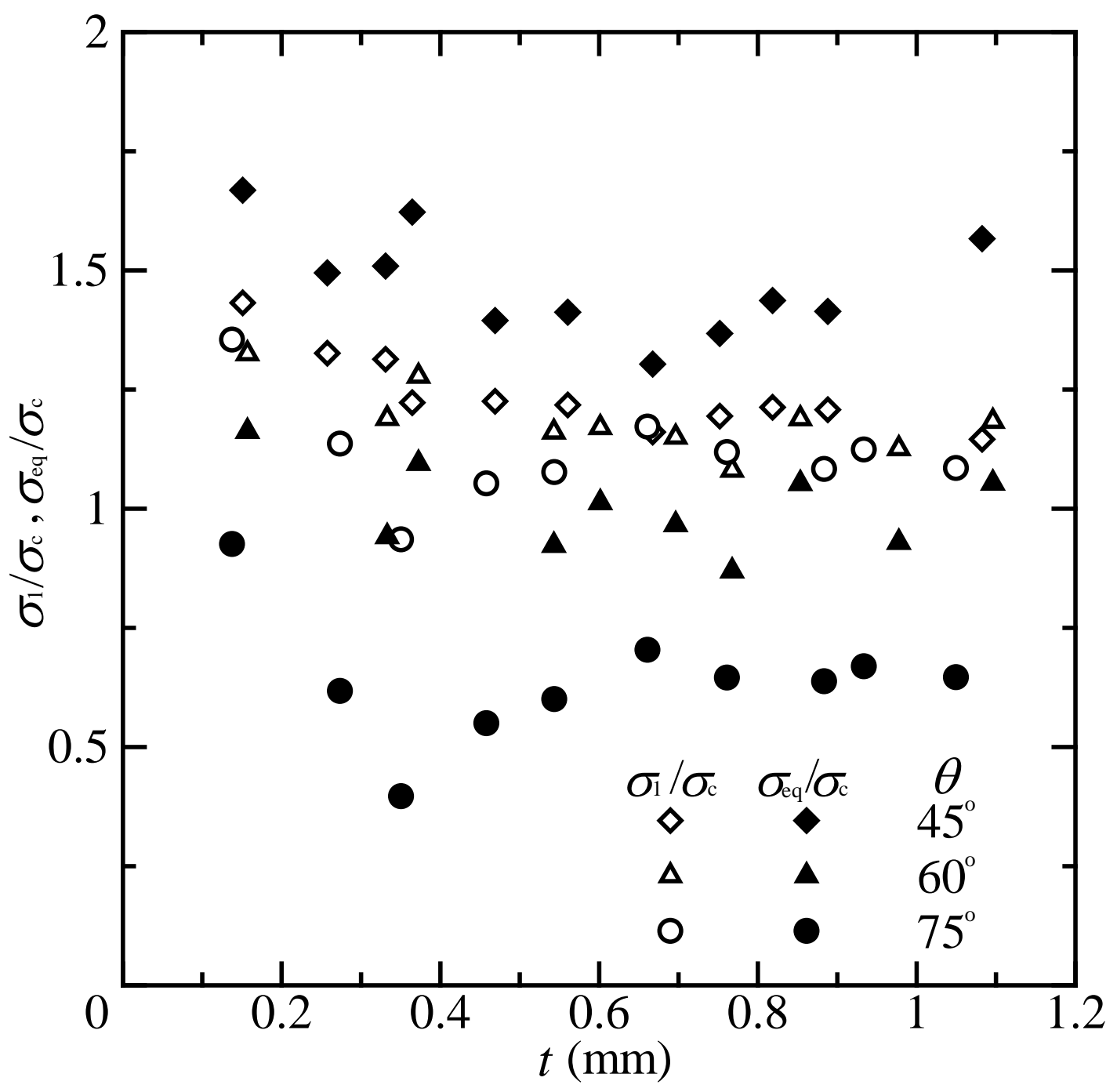

Fig. 11 Comparison between two failure criteria. 


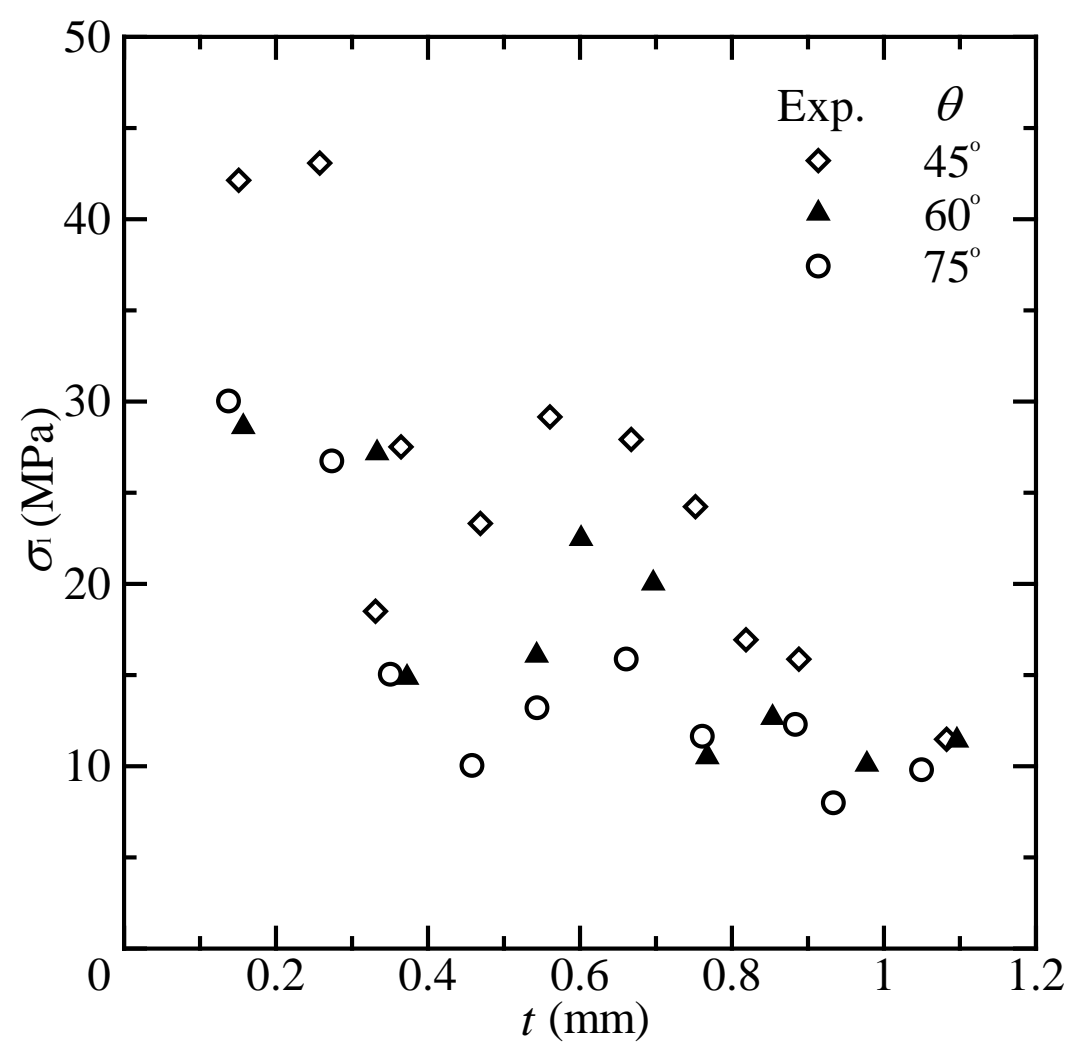

(a) Maximum principal stress.

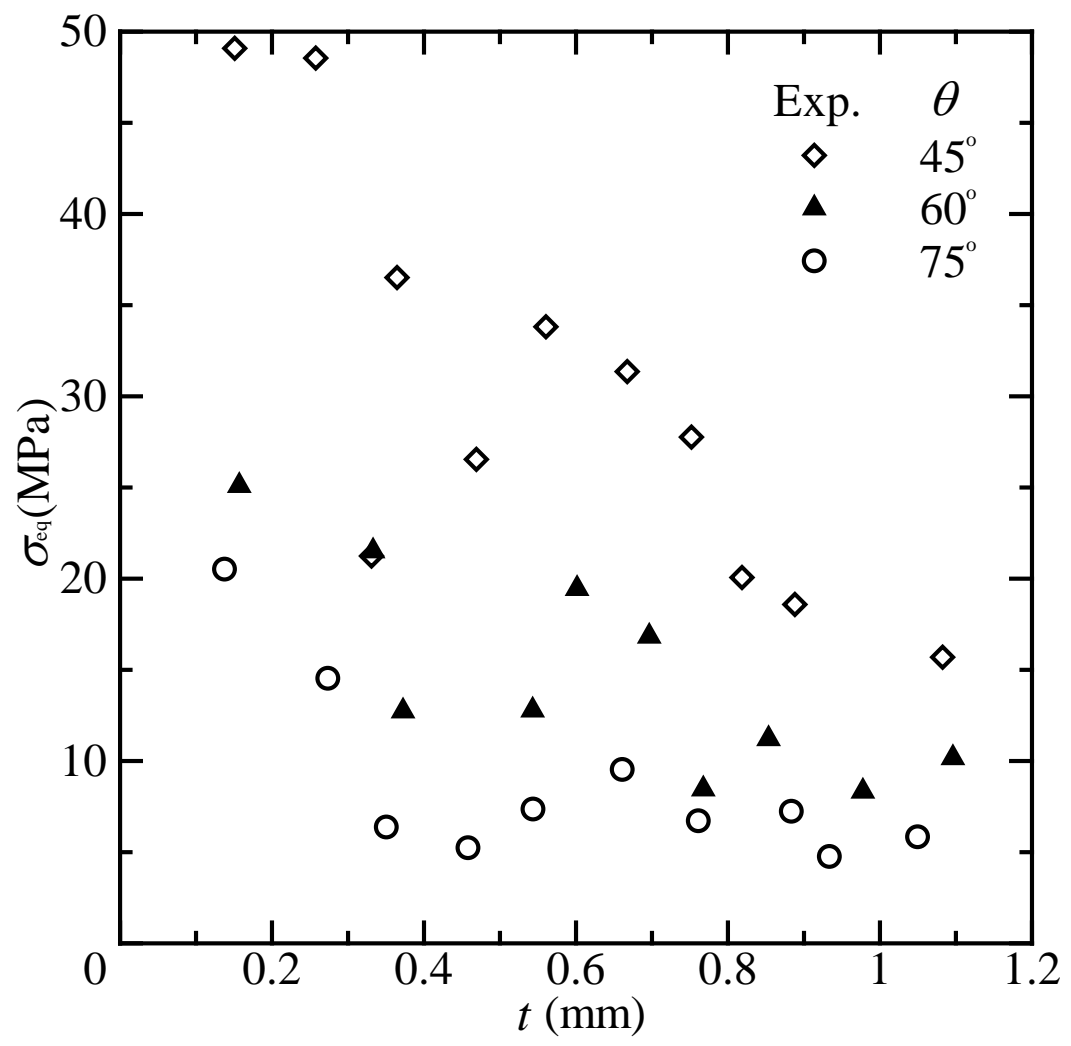

(b) Mises equivalent stress

Fig. 12 Failure criterion against bond thickness 


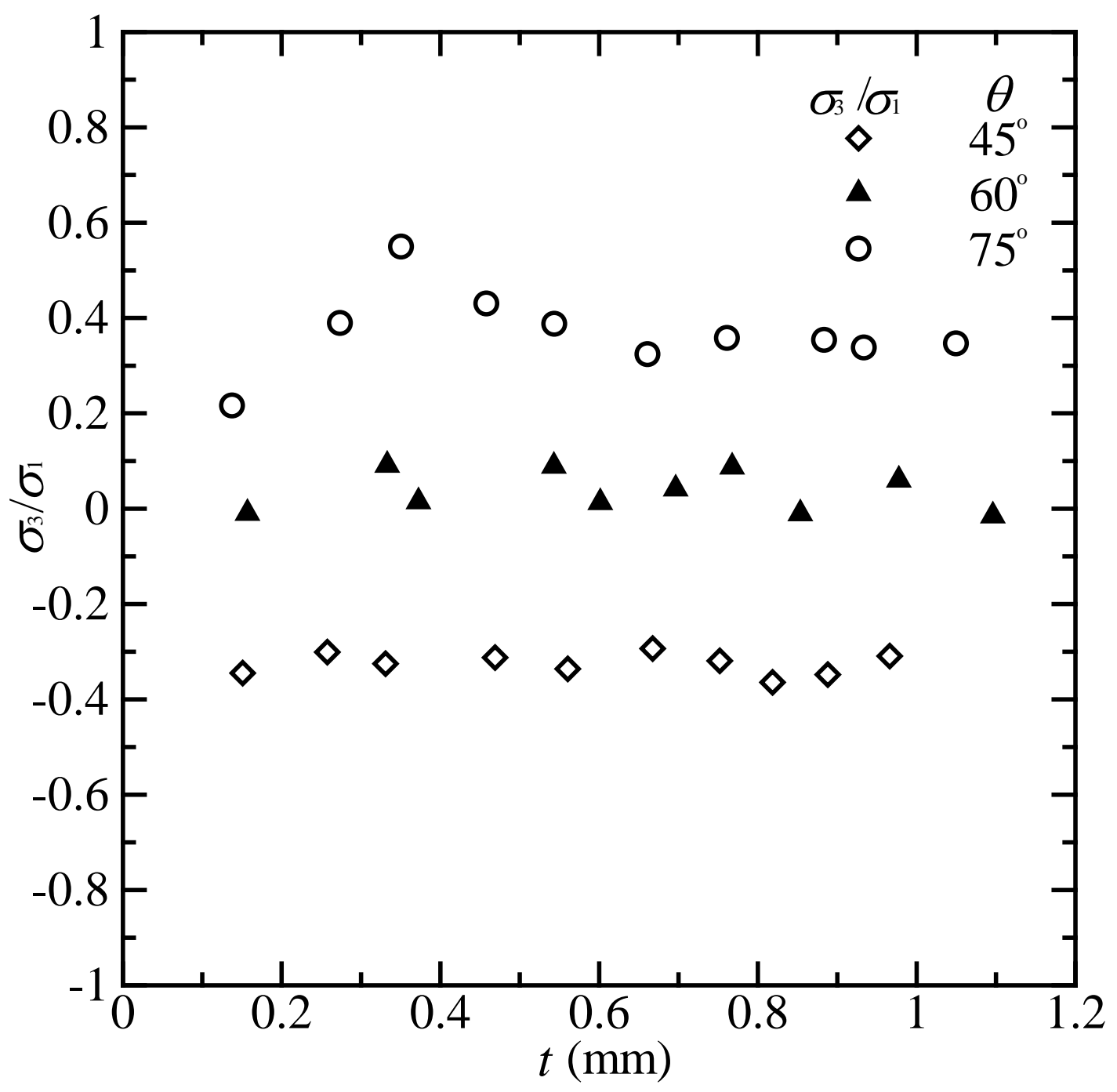

Fig. 13 Stress multiaxiality parameter against bond thickness. 


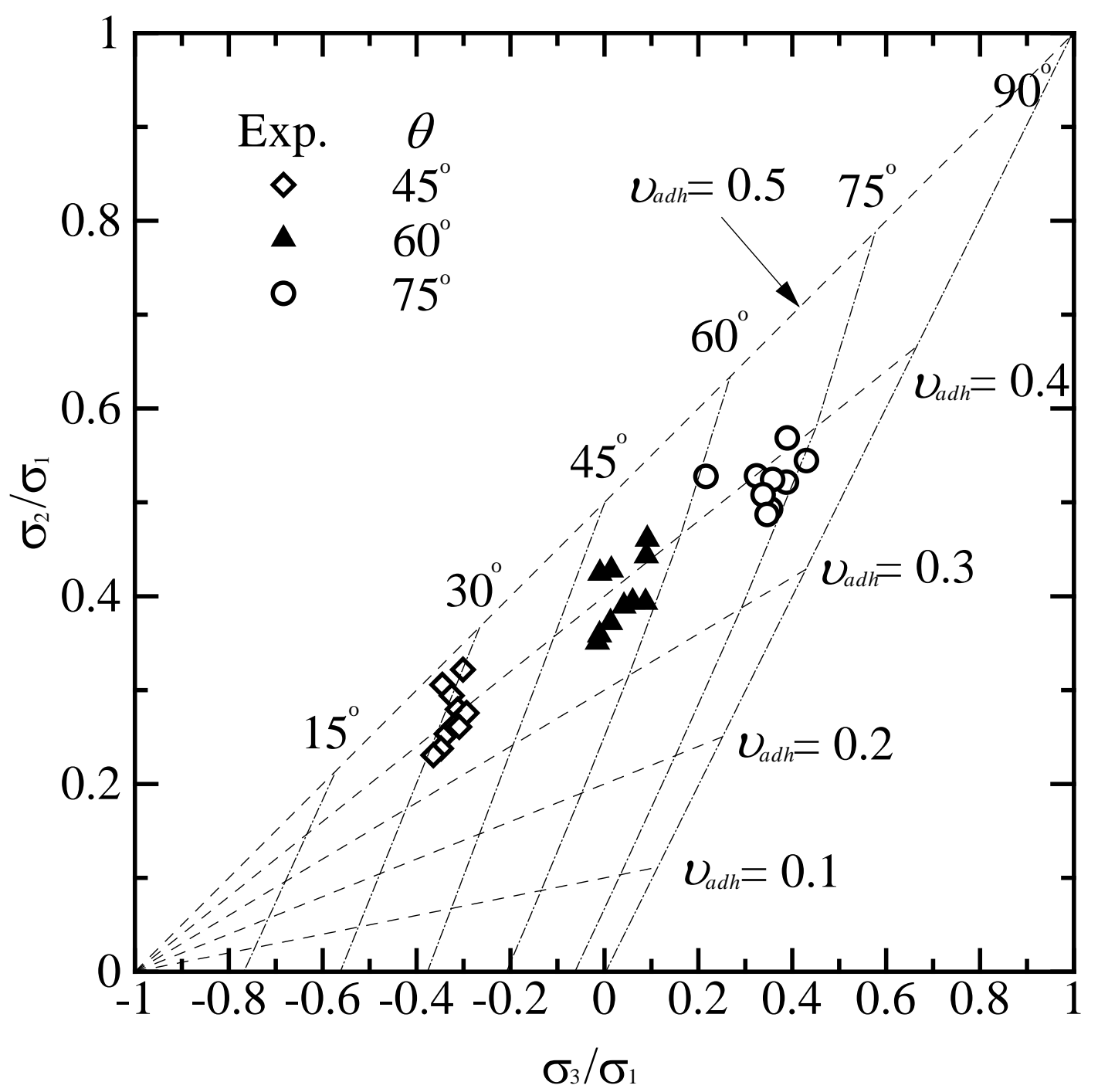

Fig. 14 Stress multiaxiality of epoxy adhesive layer in scarf joints. 


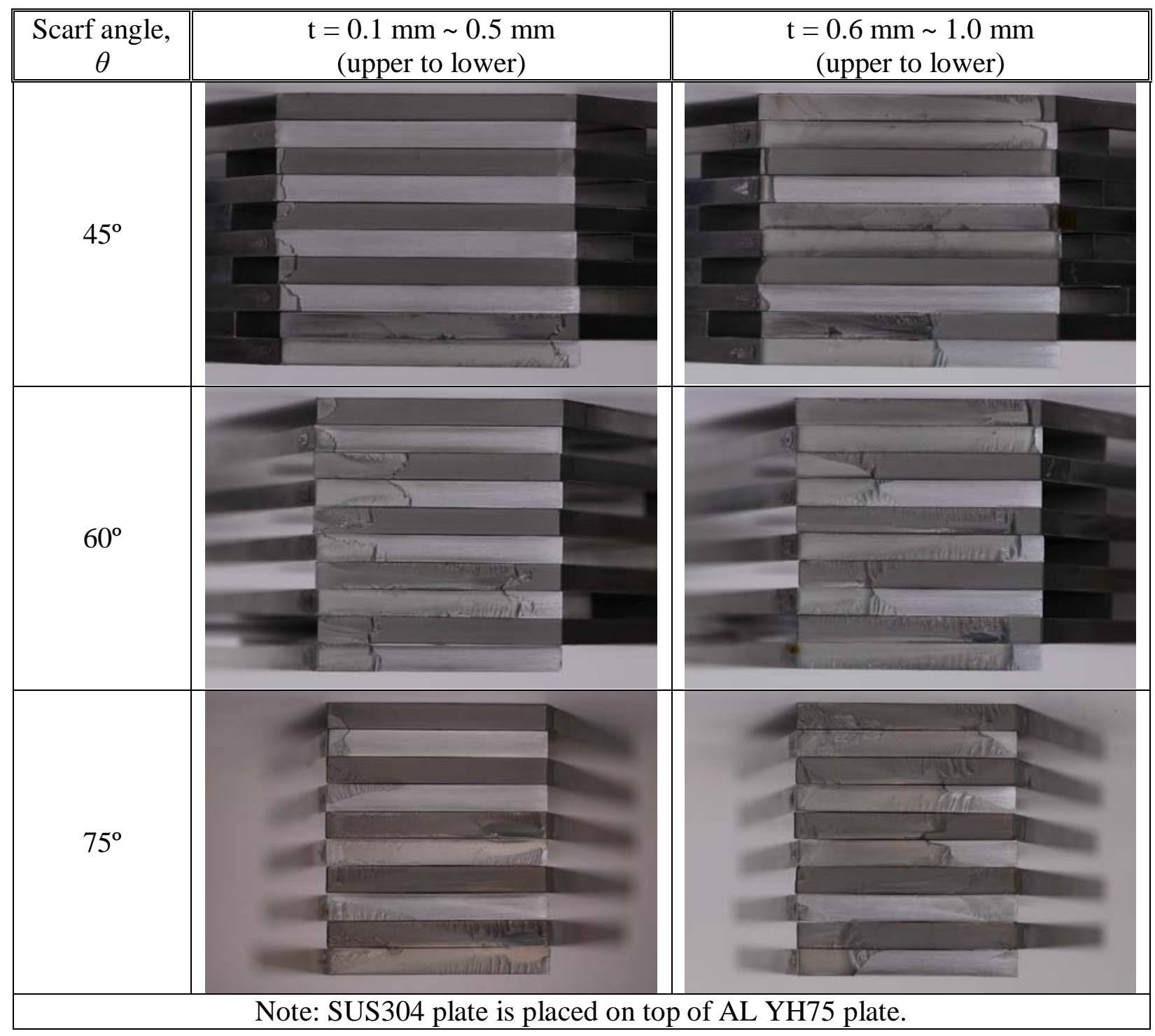

Fig. 15 Failure surface of adhesive layer in scarf joints. 


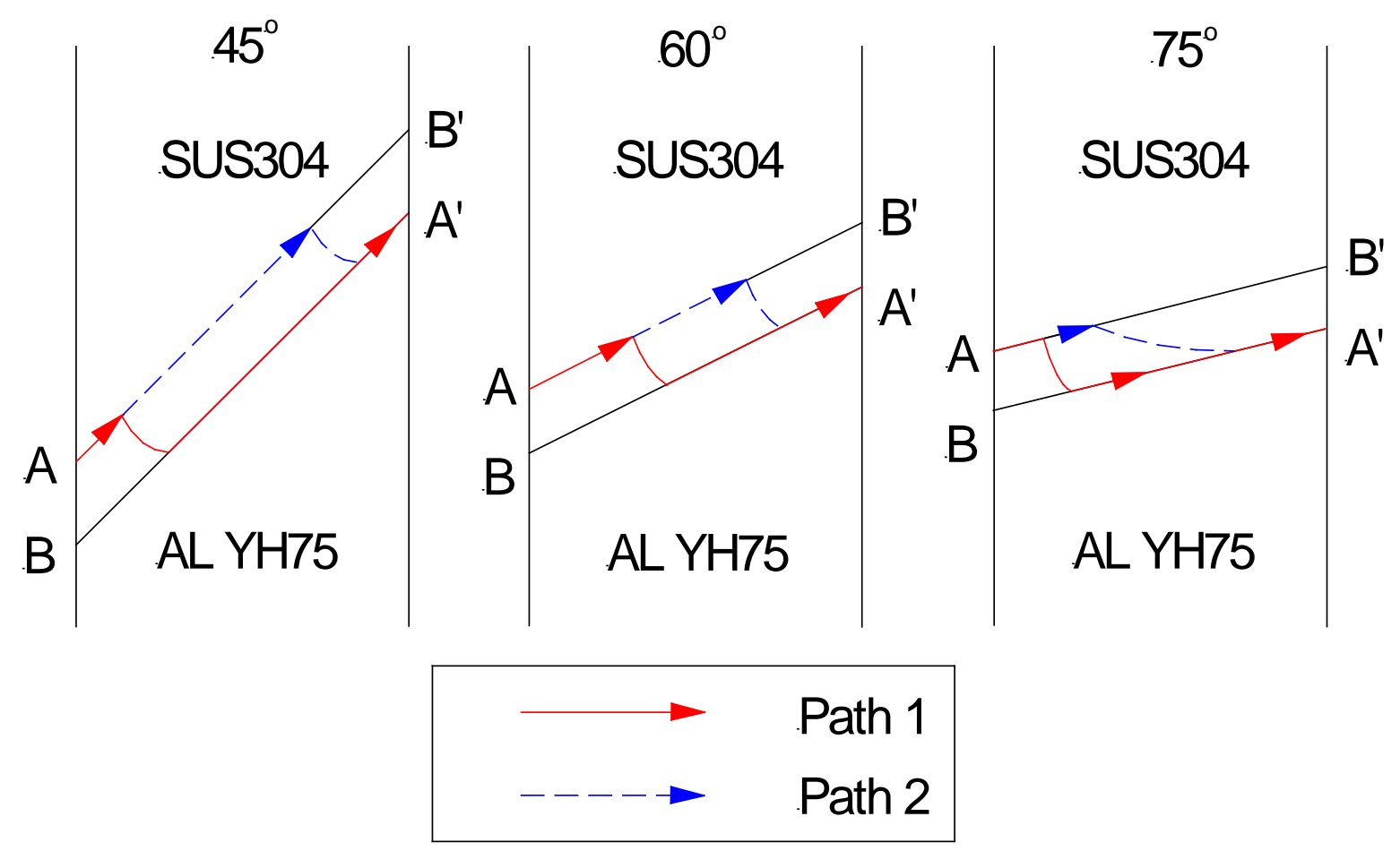

Fig. 16 Schematic of failure paths of adhesive layer in scarf joints. 


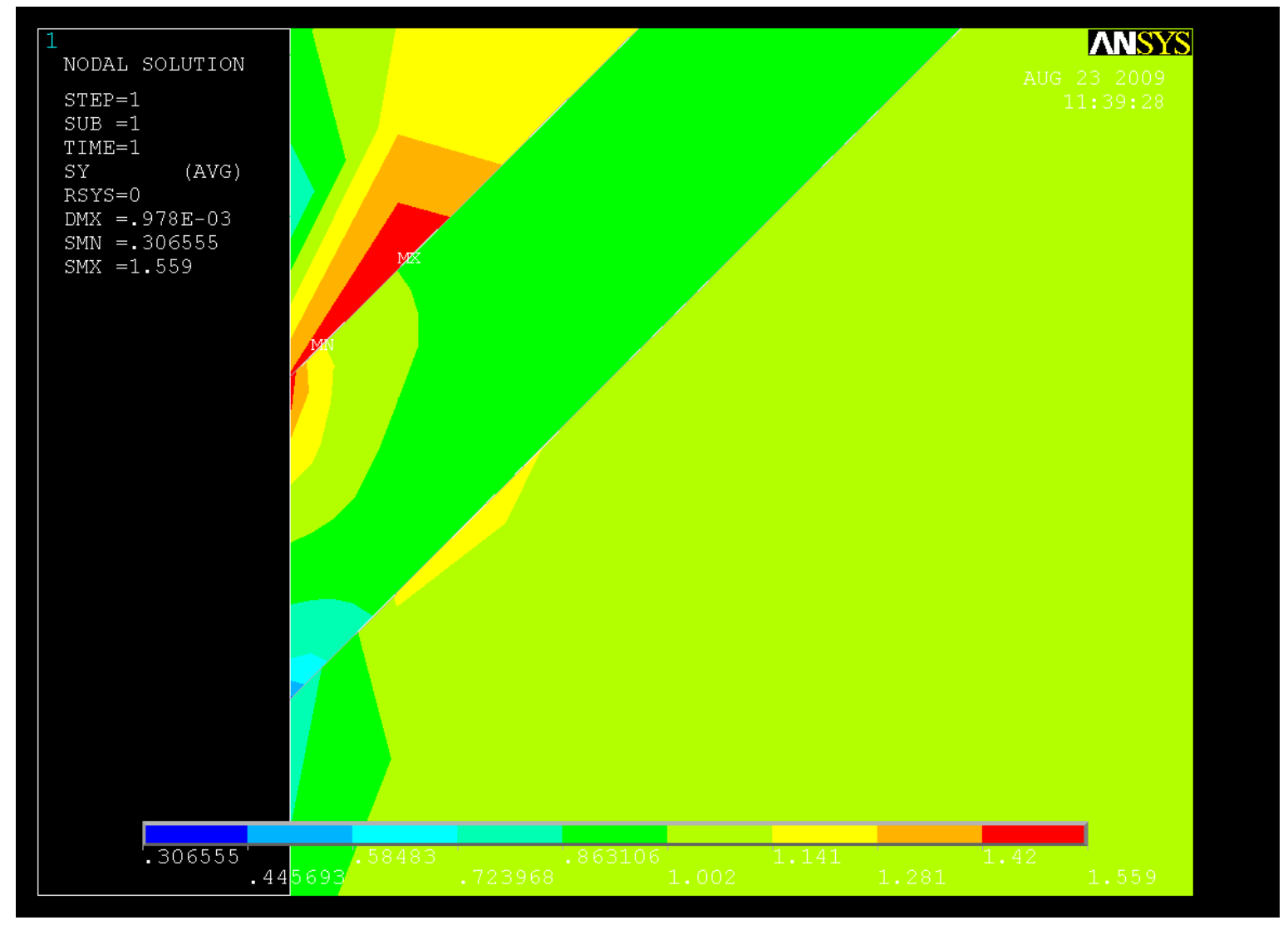

(a) Left corner.

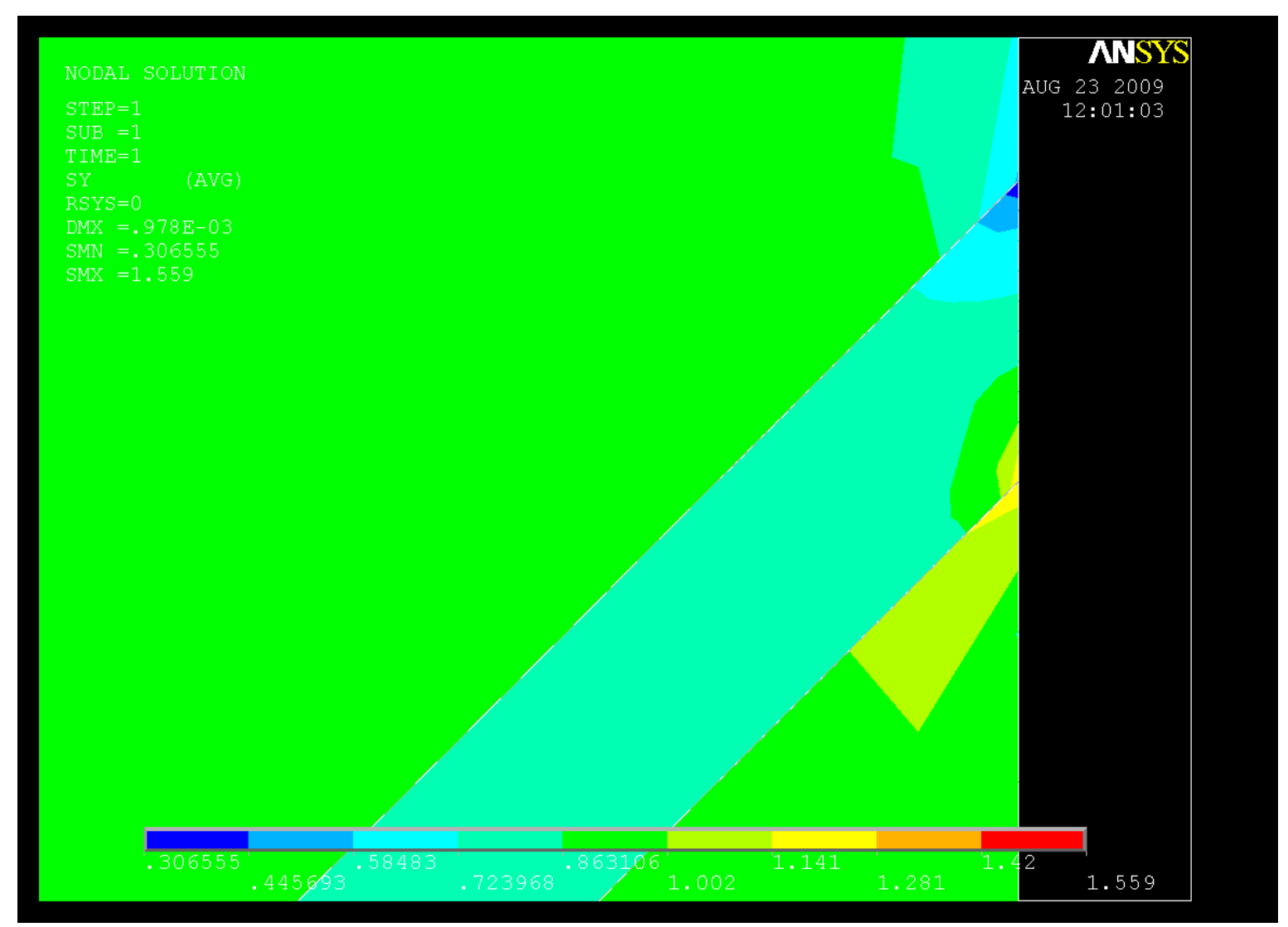

(b) Right corner

Fig. 17 Stress-y contour in scarf joints having $45^{\circ}$ scarf angle. 


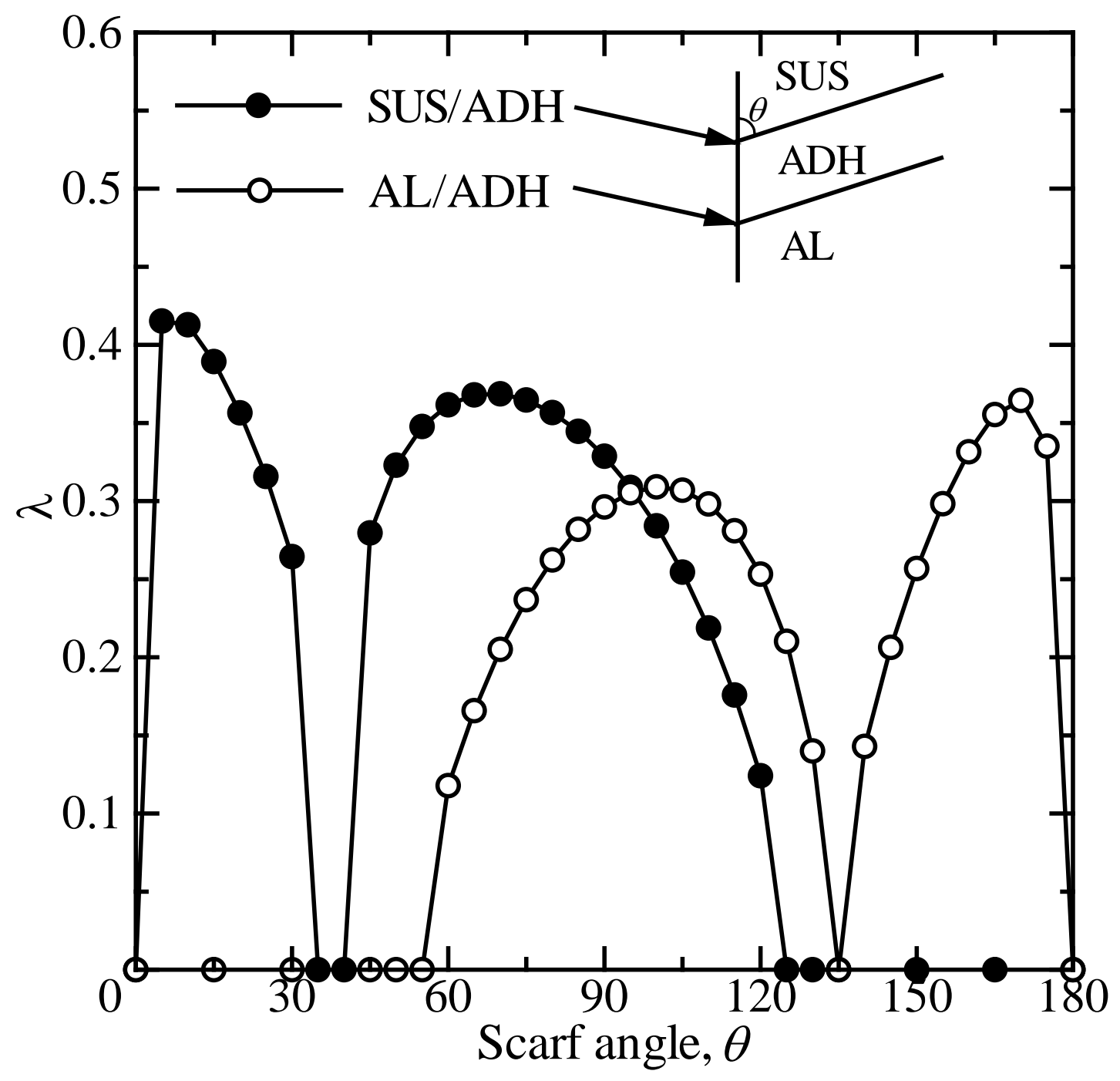

Fig. 18 Order of stress singularity, $\lambda$ at interface corner. 


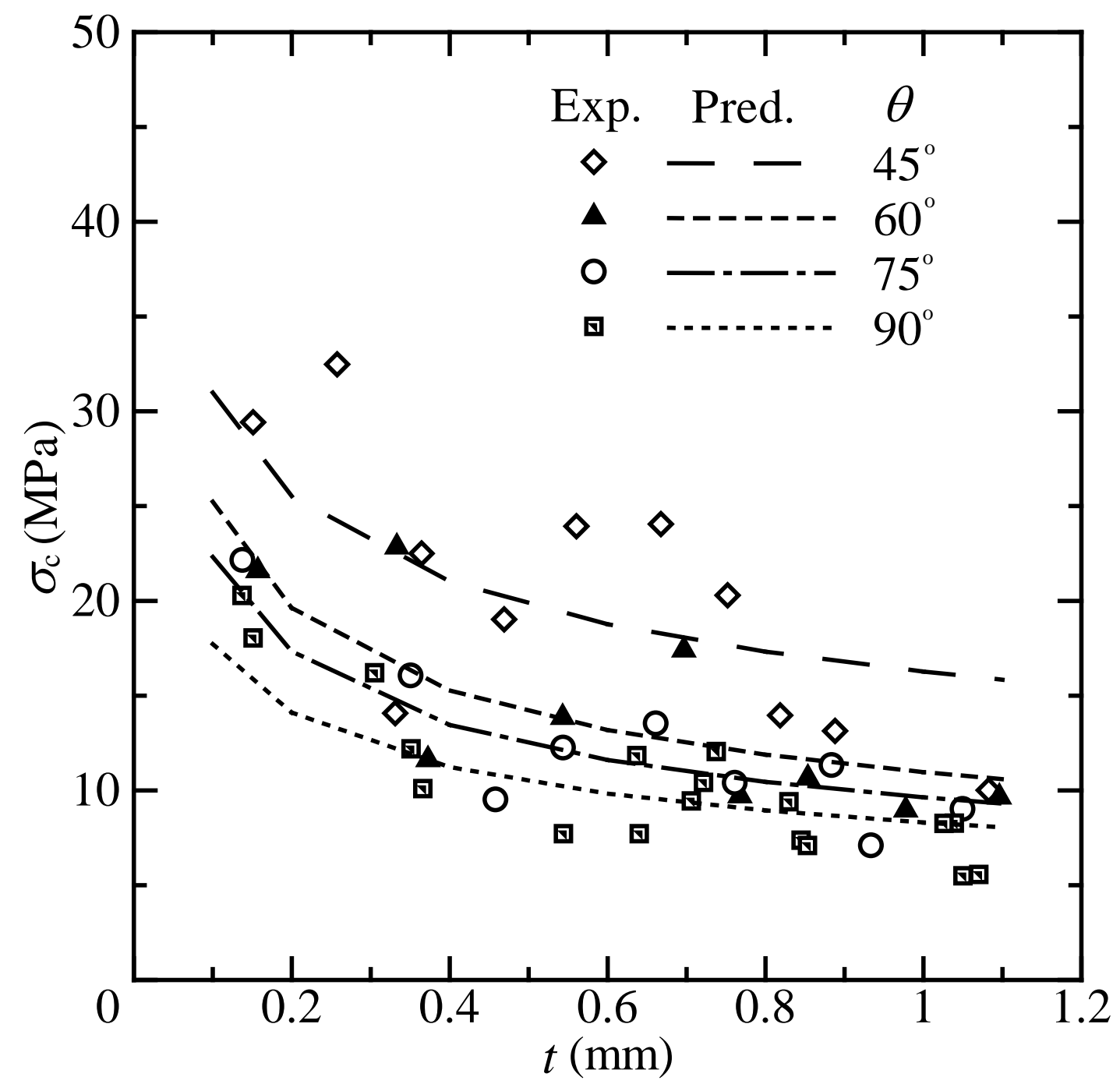

Fig. 19 Failure stress of scarf joints against bond thickness and prediction curves based on $\mathrm{Hc}$ parameter. 